\title{
Analysis on the Extreme Heat Wave over China around Yangtze River Region in the Summer of 2013 and Its Main Contributing Factors
}

\author{
Jin Li, ${ }^{1}$ Ting Ding, ${ }^{2}$ Xiaolong Jia, ${ }^{2,3}$ and Xianchan Zhao ${ }^{4}$ \\ ${ }^{1} 91867$ Troops of PLA, Yiwu 322000, China \\ ${ }^{2}$ Laboratory for Climate Studies, National Climate Center, China Meteorological Administration, Beijing 100081, China \\ ${ }^{3}$ Collaborative Innovation Center on Forecast and Evaluation of Meteorological Disasters, Nanjing University of \\ Information Science \& Technology, Nanjing 210044, China \\ ${ }^{4}$ Yiwu Meteorological Bureau, Yiwu 322000, China
}

Correspondence should be addressed to Ting Ding; dingting@cma.gov.cn

Received 12 January 2015; Revised 15 June 2015; Accepted 21 June 2015

Academic Editor: Guillermo Baigorria

Copyright $\odot 2015$ Jin Li et al. This is an open access article distributed under the Creative Commons Attribution License, which permits unrestricted use, distribution, and reproduction in any medium, provided the original work is properly cited.

In the summer of 2013, a rare extreme heat wave occurred in the middle and lower reaches of the Yangtze River in China. Based on high resolution reanalysis data from ECMWF, comprehensive analyses on the associated atmospheric circulation and the sea surface temperature anomaly (SSTA) were provided. The stable and strong West Pacific Subtropical High (WPSH) was the direct cause for the heat wave. The WPSH had four westward extensions, which brought about four hot spells in southern China. The South Asia High $(\mathrm{SAH})$ at $150 \mathrm{hPa}$ was more eastward and more northward than normal. The strong Hadley circulation in the central and western Pacific and the anomalous easterlies at $500 \mathrm{hPa}$ and $250 \mathrm{hPa}$ in the middle and high latitudes were favorable for more hot days (HDs). The total HDs in the middle and lower reaches of the Yangtze River had close relationships with the zonal wind anomalies in the middle and high latitudes, the SSTA in the Indian Ocean and Pacific, and the dry soil conditions of the Yangtze River Valley in spring and summer. The anomalies of the tropical, subtropical, and polar circulation and the underlying surfaces could be responsible for this extreme heat wave.

\section{Introduction}

The Fifth Assessment Report of Intergovernmental Panel on Climate Change (IPCC) indicates that new analyses continue to support the Fourth Assessment Report and IPCC Special Report on Managing the Risks of Extreme Events and Disasters to Advance Climate Change Adaptation (SREX) conclusions that there is medium confidence that globally the length and frequency of warm spells, including heat waves, have increased since the middle of the 20th century although it is likely (high confidence) that heatwave frequency has increased during this period in large parts of Europe, Asia, and Australia [1]. The heat wave stressed the delivery of water and energy resources and had significant morbidity and mortality impacts on humans and livestock [2-5]. Therefore, heat wave events have attracted considerable attention during recent years.

In recent years, especially after the European heat wave in 2003, many studies analyzed the magnitudes, durations, impacts associated with heat waves, and the causes of hot spells. The main features of European heat wave in 2003 summer were described and discussed in detail in the study by Feudale and Shukla [6]. Model simulations indicated that hot summers could be more frequent in a future warmer climate, and, therefore, the European heat wave of 2003 summer might give an indication of the nature of heat waves that could occur due to global warming [7-9]. Sea surface temperature anomaly (SSTA) was one of the possible factors in enhancing the heat wave in Europe $[6,10]$. The anomalous 2010 Russian heat wave that caused adverse 
impacts exceeded the amplitude and spatial extent of the previous hottest summer in 2003 [11-13]. The principal factor contributing to the heat wave magnitude was a severe rainfall deficit during antecedent and concurrent seasons related to a La Niña event [14].

There were a large number of previous studies on heat wave events and the associated atmospheric circulation in China. Significant increasing trend of the frequencies of heat waves in China was found in recent decades [15-17]. It was advantageous to the occurrences of high temperature events in the south of the Yangtze Valley and South China when the Tibetan Plateau High sustained, reinforced, and continually expanded eastward and westward $[18,19]$. The continuous hot weather over southern China was associated with the variation of the West Pacific Subtropical High (WPSH). Heat wave events occurred when the WPSH manifested intensely over most of southern China from late July to August stably $[20,21]$. The descending motion provided a sunny weather in favor of the solar radiation directly down to the ground surface that led to remarkable sensible heat flux and longwave radiation near the surface, which was favorable for the persistent heat wave event in South China in the summer of 2003 [22]. The polar vortex leaning to the western hemisphere for a long time led to weakening of the cold air which influenced China, and this was one of the important reasons why the WPSH was abnormally strong and the temperature was persistently high in the south of China [23]. Weak cold air transport, northward locations of subtropical high ridgeline, and less snow cover over the Tibetan Plateau in the winter and spring of 2005/2006 were the three main direct causes for the extremely hot and dry weather over the Chongqing and Sichuan areas of China in the summer of 2006 [24]. Low-level divergence, subtropical westerly jet axis shifting northward, and the westward jet center were conducive to the occurrence and maintenance of high temperature in China in the summer of 2009 [25].

From July to August in 2013, a long-lasting high temperature event occurred in East China, in a zone extending from North China southward to the midlower reaches of the Yangtze River and to the south of the lower reaches of the Yangtze River [26]. The number of consecutive hot days (HDs) and daily maximum temperature (DMT) in many regions broke the historical extreme records and caused moderate to severe droughts in Guizhou, Hunan, Chongqing, and other provinces. Due to few rain days, little precipitation, high solar radiation, and high evaporation in the south of the Yangtze River, drought brought about devastating impact to many aspects of social life. 1610 million people and crops of $18720 \mathrm{~km}^{2}$ in Hunan province were affected, and 353.5 million people and 1.417 million livestock were in the shortage of drinking water [27]. $3520 \mathrm{~km}^{2}$ crops had no harvest, and direct economic losses were 14.3 billion [27]. However, there were few studies on the anomaly of the thorough meteorological situation associated with the heat wave event in 2013. Here, we take a comprehensive diagnostic analysis on the 2013 summer heat wave in the middle and lower reaches of the Yangtze River in China. This paper will mainly focus on the characteristics and causes of this extreme heat wave event, in order to provide a reference to the forecasting of extreme hot spell events in the future.

\section{Data}

The temperature records were chosen from the daily observations of 752 stations during the period 1951-2013 from the National Meteorological Information Center of the China Meteorological Administration [28-30]. The datasets had been quality-controlled and used in numerous previous studies [31-37]. The stations were evenly distributed in the plains to the east of $95^{\circ} \mathrm{E}$. Because of numerous missing data before 1961 [38], the daily series of summer for 19612013 were analyzed in the present paper. Stations with more than 1-day missing records during June-August in every month were excluded. Finally, 533 stations were used for subsequent analysis. The analyses of atmospheric circulation in association with heat waves were based on the latest ECMWF ERA-Interim global reanalysis data with $0.75^{\circ} \times 0.75^{\circ}$ spatial resolution on 60 vertical levels from the surface up to $0.1 \mathrm{hPa}$ and $6 \mathrm{~h}$ temporal resolution for 1979-2013, and the sea surface temperature (SST) analyses were also chosen from the ERA-Interim data, which were downloaded from http://www.ecmwf.int/en/research/ climate-reanalysis/browse-reanalysis-datasets.

Relative indices of high temperature extremes were considered in the present paper. A hot day (HD) was defined if the temperature exceeded the 90th percentile of the local daily temperature climatology, as applied in IPCC [39] and many previous studies [40-44]. The least squares method was applied to fit the linear trend and the statistical $t$-test was used to test the significance of correlation coefficient for two time series $[45,46]$. The climatic value was the average of values during 1981-2010.

\section{The Characteristics of the Heat Wave in 2013}

In 2013, the summer average temperature in China was $21.7^{\circ} \mathrm{C}$, which was $0.7^{\circ} \mathrm{C}$ above normal [47]. The average summer temperature in 2006 and 2010 was also $21.7^{\circ} \mathrm{C}$, which was the highest since 1961 [47]. For 8 provinces from the south of the Yellow River to the middle and lower reaches of the Yangtze River, the average temperature $\left(28.0^{\circ} \mathrm{C}\right)$ was the highest since 1961 , with $1.6^{\circ} \mathrm{C}$ above normal [47]. The average temperature, the average maximum temperature and the average minimum temperature over the middle and lower reaches of the Yangtze River broke the records in the late 50 years [48]. In 23 provinces of the Yangtze River Valley, extreme high temperature events occurred in 530 meteorological stations, and 206 stations reached the highest level in the past 50 years (the highest daily maximum temperature of $44.1^{\circ} \mathrm{C}$ was recorded in Xinchang in the south of the Yangtze River). Record-breaking consecutive extreme hot temperature events were observed in 144 stations, including Changsha (48 days), Hengshan (48 days), and Anren (45 days) [47]. According to the report of China Meteorology Daily, the heat wave covered an area of 3.177 million $\mathrm{km}^{2}$ for 
the period ending on 30 July 2013 [49]. Therefore, the heat wave over the middle and lower reaches of the Yangtze River Valley in China was long-lasting, severe, and affected a large area with great harm in the summer of 2013.

In order to characterize the magnitude and duration of the 2013 summer hot spell, the analysis approach in Figure 1 was similar to the previous study on heat wave by Barriopedro et al. [11]. Figure 1 shows the spatial pattern of the highest value of DMT anomalies averaging in different time scales and the anomaly of the total HDs in 2013 summer in China. Figures 1(a) to 1(e) revealed that the center of the exceptional warmth at all temporal scales was along the reaches of the Yangtze River. The daily and weekly positive anomalies were particularly pronounced, exceeding the 90th percentile during $1961-2013$ by above $2^{\circ} \mathrm{C}$. The biweekly to seasonal positive anomalies exceeded the 90 th percentile by about $1^{\circ} \mathrm{C}$. In Figure 1(f), the spatial distribution of the HD anomaly in 2013 was similar to the distribution in Figures 1(a) to $1(\mathrm{e})$. The center of positive anomaly for HDs mainly located along the reaches of the Yangtze River, with 10 days more than the climatic average and about one week more than the 90th percentile threshold. In Chongqing, Shanghai, and the middle and northern of Zhejiang province, the HDs exceeded the climatic average by more than 25 days and exceeded the 90th percentile by over 10 days. Because of the sparse distribution of observation stations in the upper reaches of the Yangtze River, region A $\left(26.4^{\circ} \mathrm{N}-34.2^{\circ} \mathrm{N}, 105^{\circ} \mathrm{E}-122^{\circ} \mathrm{E}\right)$ in Figure 1(f) was selected to analyze the hot spells over the middle and lower reaches of the Yangtze River in the paper.

\section{The Anomaly of the Atmospheric Circulation and SST in the Summer of 2013}

4.1. The Anomaly of WPSH. The likelihood of passing into the HD threshold was more frequently reached in South China when WPSH manifested intensely over the region in the summer [21]. For the 2013 heat wave, Peng [49] indicated that the anomaly of WPSH was the major and direct reason. Figure 2 revealed that the average geopotential height anomaly series of $500 \mathrm{hPa}$ over region A had high positive correlation with the total HDs for all the stations in region A in the summer during 1979-2013. The correlation coefficient is 0.58 , significant at the 0.01 level. The average geopotential height anomaly of region A in the summer of 2013 was the second highest for 1979-2013, and the total HDs in 2013 were the peak in recent years. In Figure 2, the total HDs in region A presented an increasing trend. The strong heat wave events in South China became more frequent and stronger significantly in the 54 years [26]. The heat wave in the summer of 2013 may also be partly due to the global warming. Global warming altered the climatic distribution of extreme heat events, such that heat wave might become more likely to occur.

Figure 3 shows the longitude and latitude profiles of the $500 \mathrm{hPa}$ geopotential height departure from $5880 \mathrm{gpm}$ in region $\mathrm{A}$ in the summer of 2013 . The WPSH at $500 \mathrm{hPa}$ first strengthened in region $\mathrm{A}$ in mid-June and intensified in mid-July with higher geopotential height anomaly than that in mid-June. The positive geopotential height anomaly over region A reached the highest in late July to mid-August. In the end of August, the WPSH enhanced for a few days. The number of $\mathrm{HD}$ stations in region $\mathrm{A}$ increased while the positive geopotential height anomalies over region $\mathrm{A}$ were observed and reduced while the positive anomalies decreased. The four intensifications of the WPSH indicated the four hot spells in the middle and lower reaches of the Yangtze River in the summer of 2013, and the third hot spell from late July to mid-August was the most severe. This was consistent with analyses by Tang et al. [48].

The position of the WPSH ridge line at $500 \mathrm{hPa}$ was compared with the climatic position for the summer in 2013 (Figure 4). The WPSH ridge line was more northward than the climatic position in early to mid-June, and more southward from the second half of July to early August and in late August. In mid-June, the WPSH ridge line arrived near $28-31^{\circ} \mathrm{N}$, which was 5-8 latitudes more northward than the climatic position. From late July to early August, the ridge line was 4-6 latitudes more southward than the climatic position and stabilized in the vicinity of $25-26^{\circ} \mathrm{N}$. The WPSH ridge line was 2 latitudes more northward than the climatic position in June, 1 latitude more southward in July, and 1.5 latitudes more southward in August. The WPSH was maintained in the vicinity of $25-30^{\circ} \mathrm{N}$ during the whole summer, which caused the long-lasing heat wave in region A. Meanwhile, the anomalous position of the WPSH precluded it susceptibility to weakening by tropical easterly wave or typhoons, which could disrupt or end the heat wave. The easterly wave represented a kind of wave migrating westward through deep easterlies on the south side of a subtropical high over the western Pacific and South Asia [50]. Tropical easterly waves were a type of atmospheric trough oriented north to south, which moved from east to west across the tropics and sometimes could lead to typhoons in western Pacific Ocean.

4.2. The Anomaly of the South Asia High. South Asia High $(\mathrm{SAH})$ was a strong and steady atmospheric anticyclone in the upper troposphere and lower stratosphere over southern Asia in the summer and had close relationship with the atmospheric circulation of northern hemisphere and Asia [51-56]. In particular, it had great impacts on the summer heat waves in China $[18,19,25,56]$. The studies by Wu et al. [53] and Li et al. [57] revealed that the descending air motion prevailed in the Yangtze Valley while the ridge line of the SAH was more northward. Zhu et al. [58] pointed out that the WPSH strengthened and extended westward, when the SAH strengthened and moved eastward. The precipitation was above normal in northern China and below normal in southern China in the summer of 2013 [47]. The release of the latent heat of condensation over the northern part of China enhanced the geopotential height anomaly and caused the divergence in the upper troposphere and lower stratosphere [47]. The southward divergent air flows descended over the WPSH and made the WPSH continue to be strong and westward [47]. Figure 5 shows the distribution of geopotential height and the anomaly at $150 \mathrm{hPa}$ in the summer of 2013, and the $14360 \mathrm{gpm}$ isoline represents the climatological position of SAH. The center of the SAH was located near $80^{\circ} \mathrm{E}$, and the high value of geopotential height anomaly in Figure 5 was 


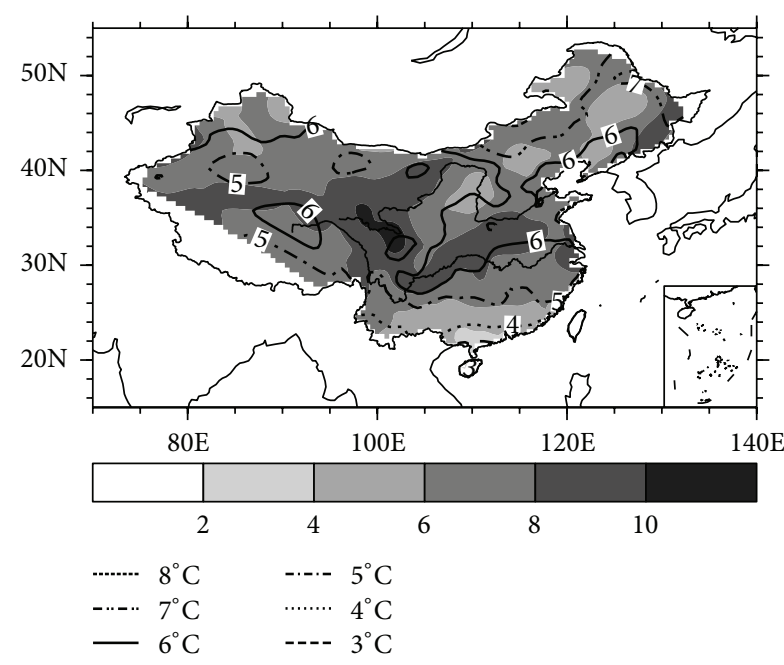

(a)

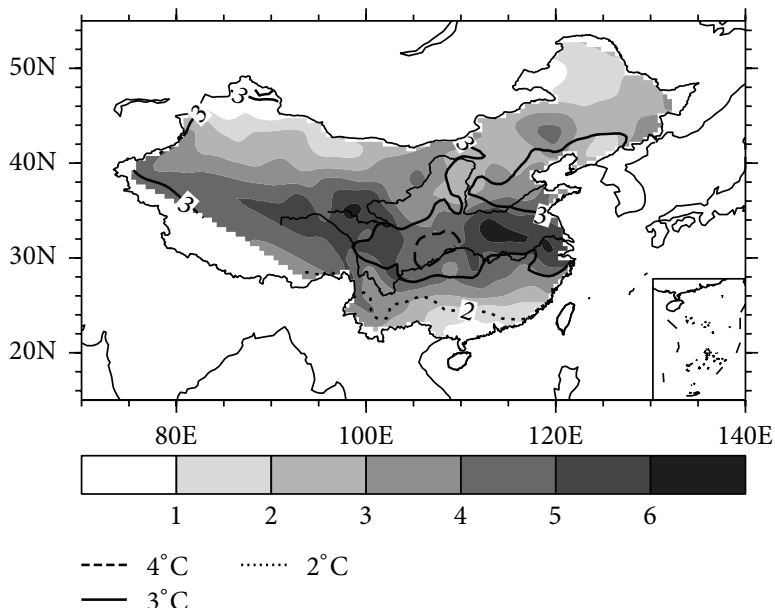

(c)

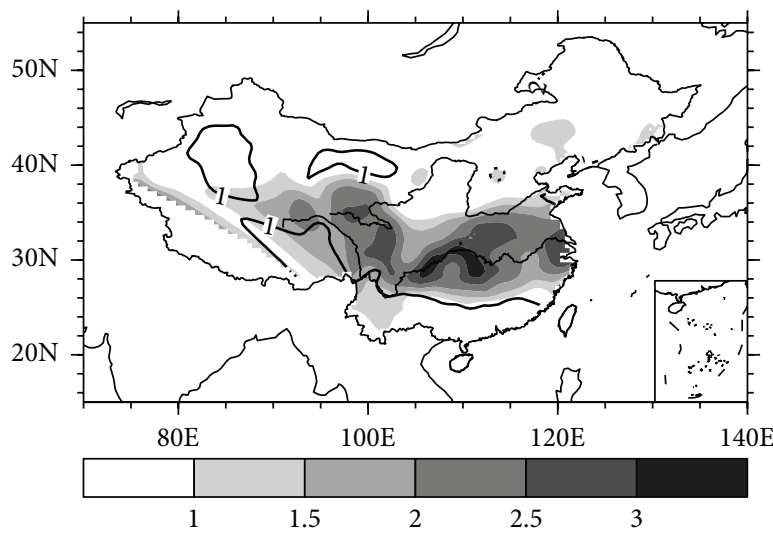

…... $2^{\circ} \mathrm{C}$

$-1^{\circ} \mathrm{C}$

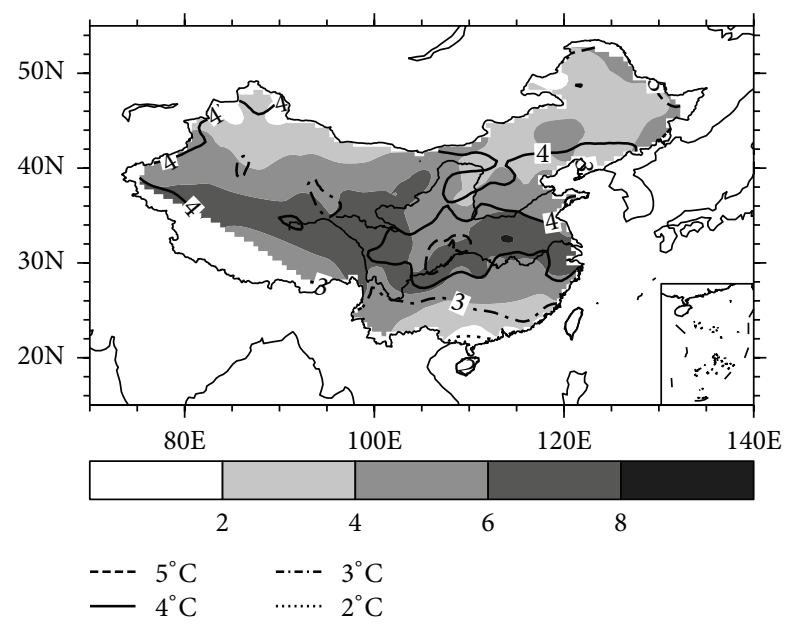

(b)

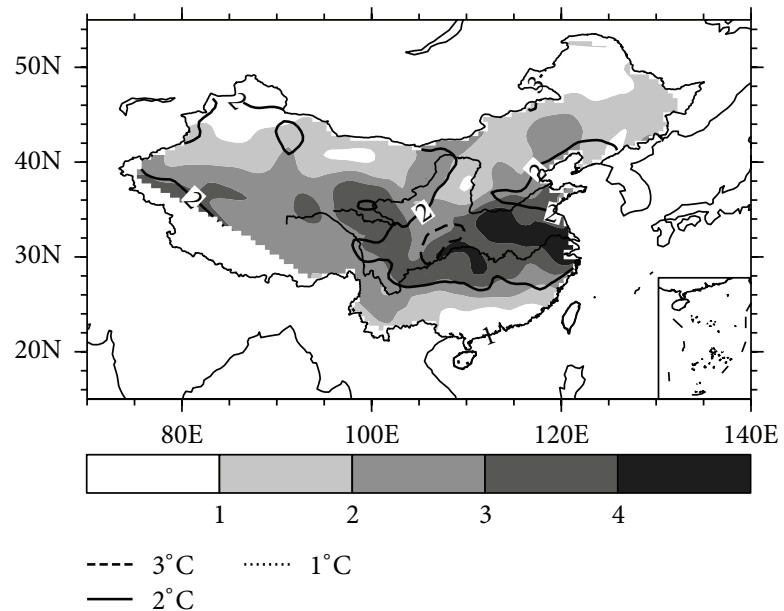

(d)

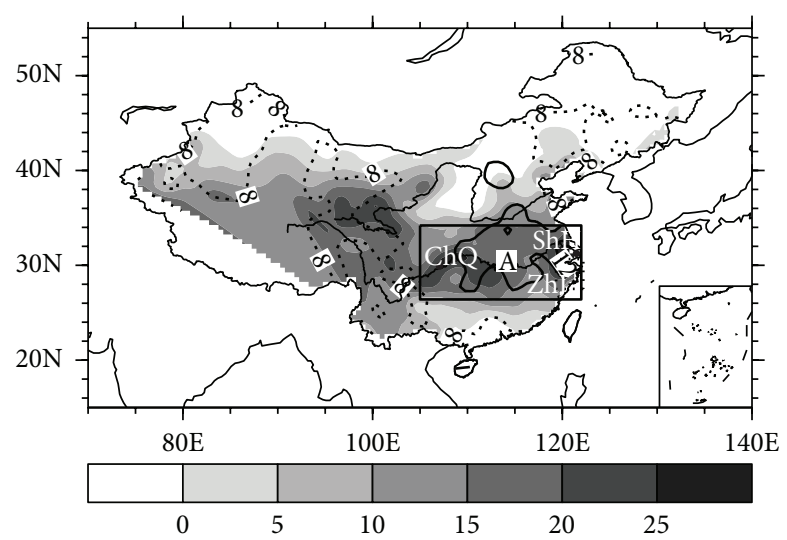

- 12 days

....... 8 days

(e)

(f)

FIGURE 1: The distribution of the highest value of DMT anomalies $\left({ }^{\circ} \mathrm{C}\right)$ running-averaging (a) daily, (b) weekly, (c) biweekly, (d) monthly, and (e) seasonally and in the anomaly of the total HDs (days) in 2013 summer in China (f). The shaded areas denote the highest value of DMT anomaly, and the lines denote the 90th percentile threshold of DMT anomaly for 1961-2013 for the corresponding time scales. The rectangle $\left(26.4^{\circ} \mathrm{N}-34.2^{\circ} \mathrm{N}, 105^{\circ} \mathrm{E}-122^{\circ} \mathrm{E}\right)$ in Figure $1(\mathrm{f})$ indicates region A. "ChQ," "ShH," and "ZhJ" in (f) indicate the geographical location of Chongqing, Shanghai, and Zhejiang province. 


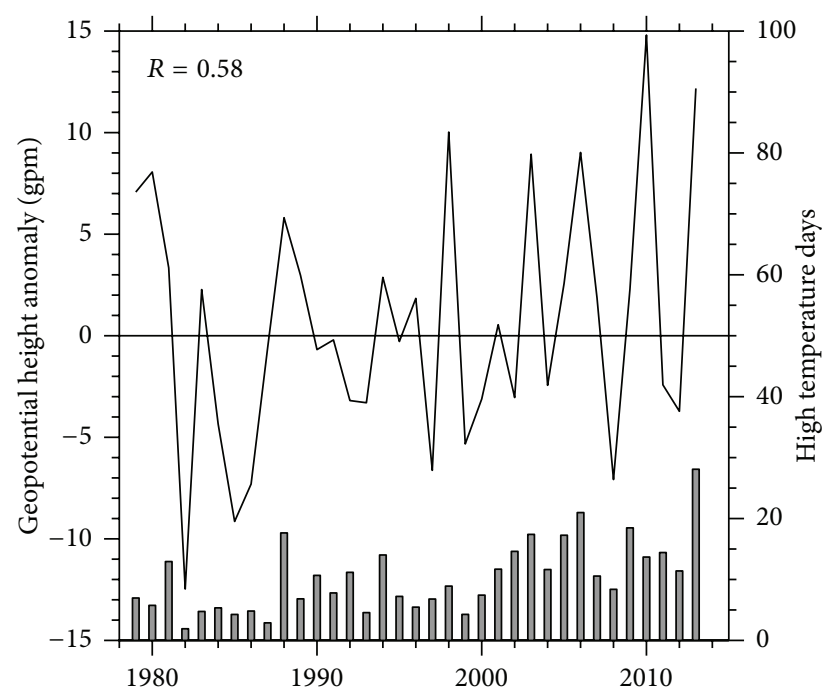

Figure 2: The anomaly of $500 \mathrm{hPa}$ average geopotential height (gpm, solid line) and the total HDs (days) of observation stations (bar) in region A in the summer of 1979-2013. The total HDs are reduced 100 times.

located in the region of the Yellow River Valley. Compared with the climatological position of $\mathrm{SAH}$, it was found that the SAH was more eastward and more northward than usual in the summer of 2013. Accompanied by the abnormal location and strengthening of the SAH, the WPSH was stronger and more westward in this summer.

In order to reveal the interrelation between troposphere and stratosphere, Figure 6 shows the time-height section of the geopotential height anomaly averaged in region $\mathrm{A}$ in the summer of 2013. There were positive anomalies from $700 \mathrm{hPa}$ up to $50 \mathrm{hPa}$ during the most time of the summer. The maximum of geopotential height anomaly was mainly found at about $150 \mathrm{hPa}$, and the downward expansion of the upper-level positive height anomaly existed. The anomaly of SAH was found in the bottom of the stratosphere and the anomaly of WPSH in the midupper troposphere. In Figure 6, four eastward extensions and strengthening of the SAH were found at $150 \mathrm{hPa}$ in the second half of June, the first half of July, late July, and late August. Meanwhile, the WPSH strengthened and expanded to the west (Figure 3 ) and then resulted in the increasing HDs in southern China.

4.3. The Anomaly of Zonal and Meridional Flows. The zonal and meridional winds were the main components of air movement, and the atmospheric circulation anomaly and the occurrences of many extreme events were associated with the anomalies of wind [21, 59-66].

4.3.1. The Anomaly of Zonal Wind. Figure 7 shows the correlation coefficient distribution between the total HDs in region $\mathrm{A}$ and $\mathrm{u}$-component anomaly and the distribution of u-component anomaly in 2013 summer. At $250 \mathrm{hPa}$, the significant negative correlation was found over the northern Kazakhstan northeastward to the north of Lake Baikal and the Yangtze River Valley, while significant positive correlation was found over Uzbekistan eastward to Northeast China. In the summer of 2013, the anomalous easterlies were observed in two regions at $250 \mathrm{hPa}$, in north of $50^{\circ} \mathrm{N}$ and south of $36^{\circ} \mathrm{N}$, with the maximum anomalies exceeding $6 \mathrm{~m} / \mathrm{s}$ and $4 \mathrm{~m} / \mathrm{s}$, respectively. The anomalous westerly was found in the region of $38-48^{\circ} \mathrm{N}$, with the maximum anomaly above $12 \mathrm{~m} / \mathrm{s}$. Comparing Figure 7(a) with Figure 7(b), the distribution of zonal wind anomaly at $250 \mathrm{hPa}$ in the summer of 2013 was favorable for HDs in region A. In Figures 7(c) and $7(\mathrm{~d})$, the distribution of correlation coefficient during 1979-2013 and u-wind anomaly in 2013 summer at $500 \mathrm{hPa}$ was similar to those at $250 \mathrm{hPa}$. At $700 \mathrm{hPa}$, the significant positive correlation was found in the south of the Balkhash Lake (located in southeastern Kazakhstan in Central Asia within the domain $73-80^{\circ} \mathrm{E}, 45-48^{\circ} \mathrm{N}$ ) and from Northeast China to the Korean Peninsula. For the mean climatology, the subtropical monsoon prevails from Southeast China to Northeast China at $700 \mathrm{hPa}$ in summer. The HDs were more in region $\mathrm{A}$ and the WPSH was more westward, when the westerly wind was stronger from Northeast China to the Korean Peninsula. The zonal air flow in the middle and high latitudes of the northern hemisphere had close relationship with the heat waves in region $\mathrm{A}$.

4.3.2. The Anomaly of Meridional Wind. In summer, the WPSH often weakened and moved eastward during the period of tropical cyclones, and the generation and tracks of tropical cyclones were closely associated with the intertropical convergence zone (ITCZ) [21]. Yang and Li [21] found that the anomaly of cross-equatorial airflow in the middle and western Pacific was one of the important causes for the extreme high temperature in southern China in the summer of 2003. In Figure 8(a), the strong southerly anomaly at the top of troposphere transported northward from the southern hemisphere to near $20^{\circ} \mathrm{N}$ and then descended, while the northerly anomaly at the bottom of troposphere blew to near $10^{\circ} \mathrm{N}$ and then ascended. The strong ascending branch was mainly located near $10^{\circ} \mathrm{S}$. The Hadley circulation of northern hemisphere was stronger in the middle and western Pacific in the summer of 2013, which contributed to the strengthening and extending westward of WPSH. The northerly anomaly in the central and western Pacific was favorable for weaker ITCZ [21]. In the summer of 2013, the northerly anomaly prevailed in the lower troposphere between $10^{\circ} \mathrm{S}$ and $20^{\circ} \mathrm{N}$ in the middle and western Pacific. The weakening of the southerly was unfavorable for the generation and development of tropical cyclones and was against the weakening of the WPSH. The average numbers of tropical cyclones generating in the ITCZ in July and August were 5.6 and 7.2, respectively, while the numbers in July 2013 and August 2013 were smaller than the climate mean, with 3 and 4, respectively [67]. At the same time, in the northern troposphere of about $28^{\circ} \mathrm{N}$ (Figure 8(a)), there was an anticlockwise circulation. The strong descending branch lied in the southern of $30^{\circ} \mathrm{N}$, and the anticlockwise circulation also strengthened the WSPH.

Figure $8(\mathrm{~b})$ shows that in Southeast Asia, the northerly anomaly prevailed below $500 \mathrm{hPa}$ between $10^{\circ} \mathrm{S}$ and $15^{\circ} \mathrm{N}$ in the summer of 2013, while the southerly anomaly mainly appeared in the north of $15^{\circ} \mathrm{N}$. The South China Sea monsoon 


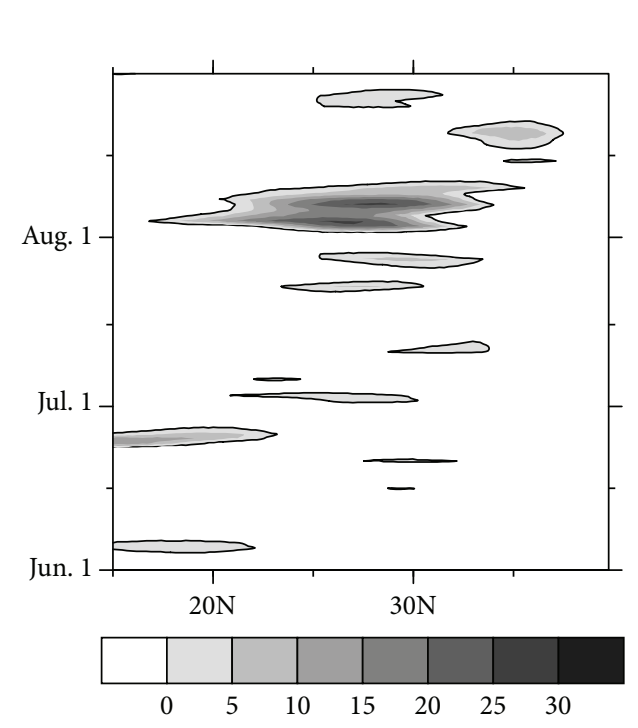

(a)

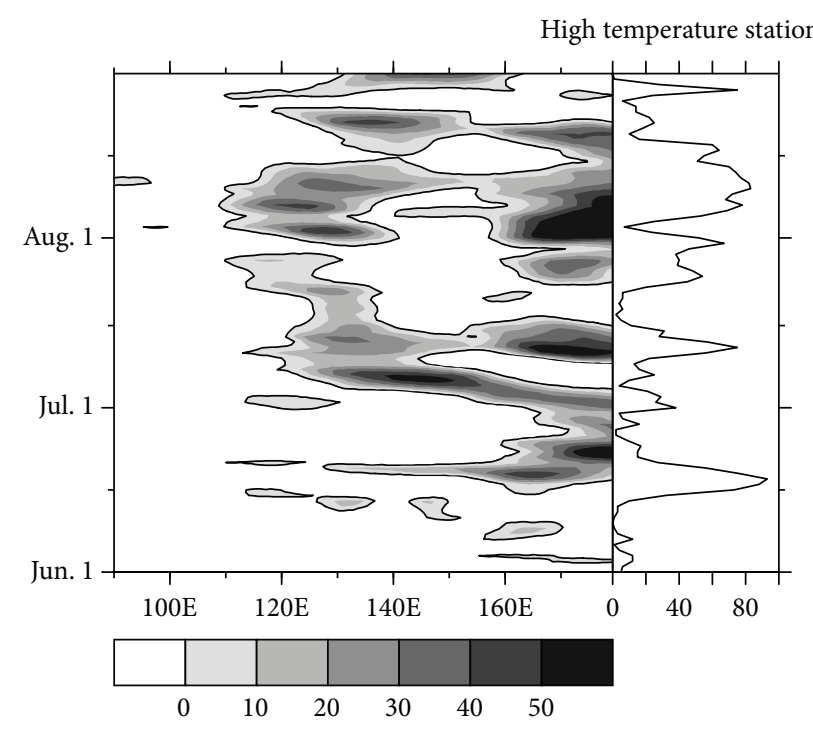

(b)

Figure 3: The $500 \mathrm{hPa}$ geopotential height departure from $5880 \mathrm{gpm}$ (shaded area, gpm) of (a) the time-latitude profile and (b) the timelongitude profile and stations affected by the heat wave in region A in the summer of 2013. In (b), the right figure denotes the number of daily total stations affected by the heat wave.

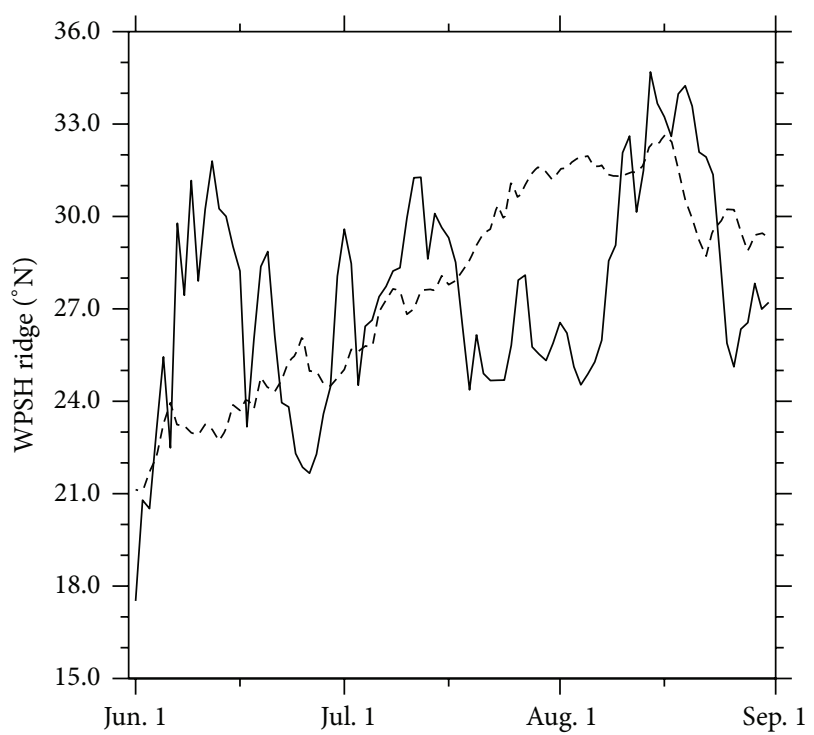

FIgURE 4: The variation of the climatic position (dashed line) and the position in the summer of 2013 (solid line) for WPSH ridge line at $500 \mathrm{hPa}$.

was weaker than usual, and the subtropical monsoon was stronger in the summer of 2013. The WPSH was more westward in summer accompanied by weak South China Sea monsoon and strong subtropical monsoon [68].

The southerly anomaly from surface to $300 \mathrm{hPa}$ was found in $26-36^{\circ} \mathrm{N}$ (the middle and lower reaches of the Yangtze River) in the summer of 2013 (Figure 8(c)). The center of the southerly anomaly tilted northward with height.

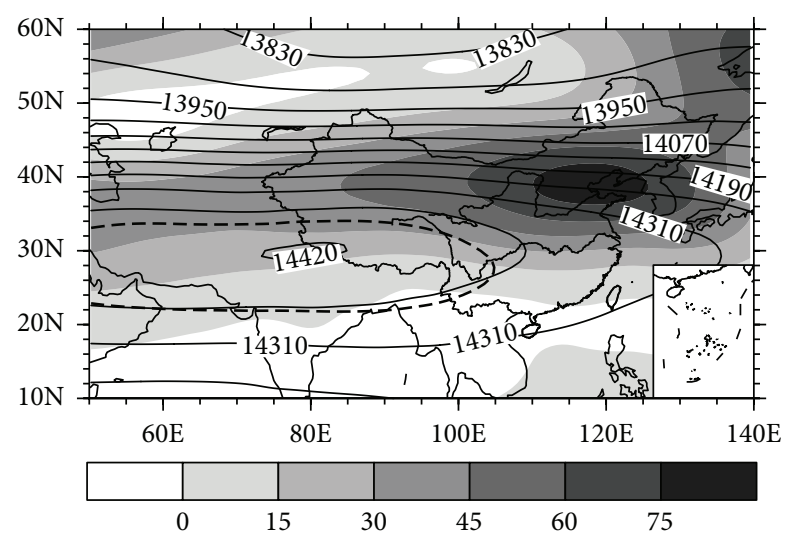

Figure 5: The distribution of geopotential height (solid line) and the anomaly (shaded area) at $150 \mathrm{hPa}$ in the summer of 2013 (gpm). The dashed line (14360 gpm) indicates the climatological position of SAH.

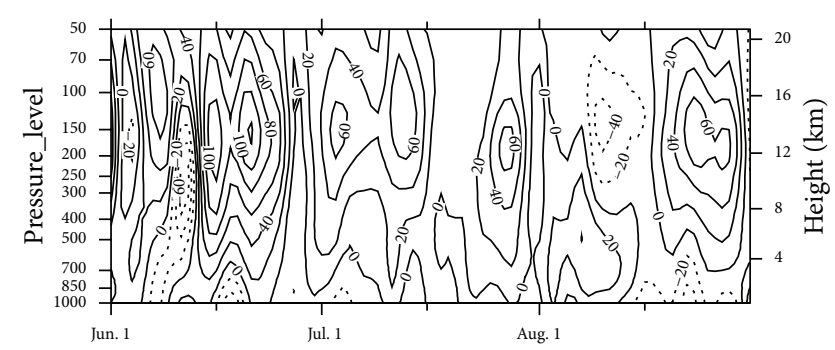

FIGURE 6: The time-height section of geopotential height anomaly averaged in the region A in the summer of 2013 (gpm). 


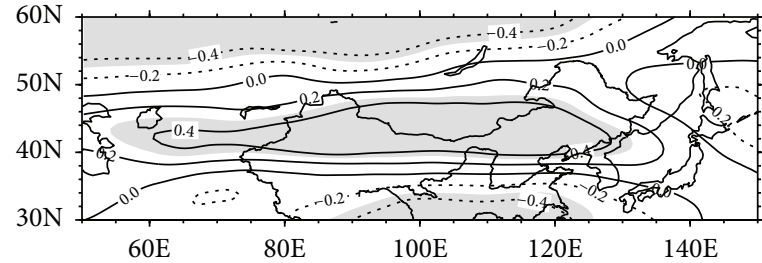

(a)

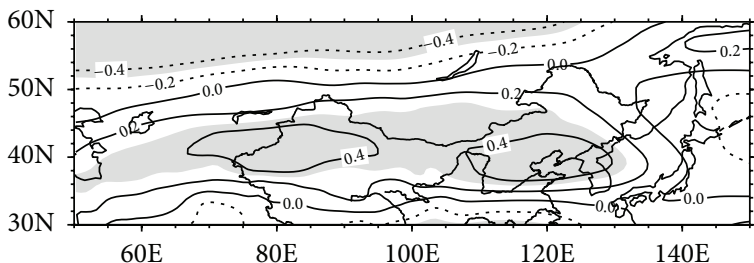

(c)

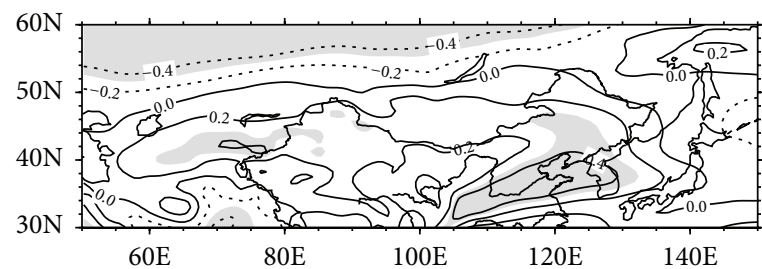

(e)

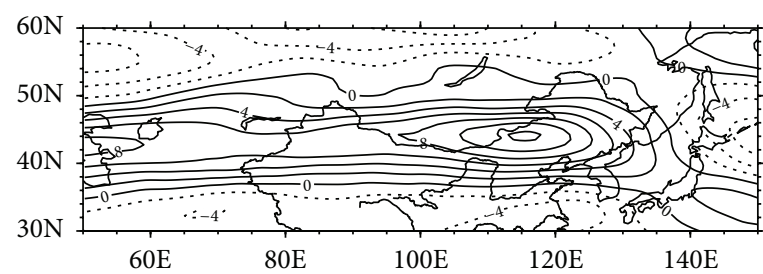

(b)

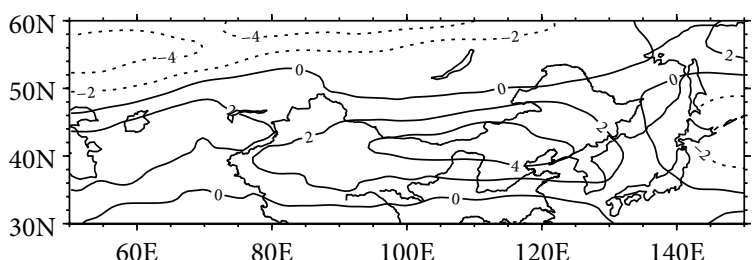

(d)

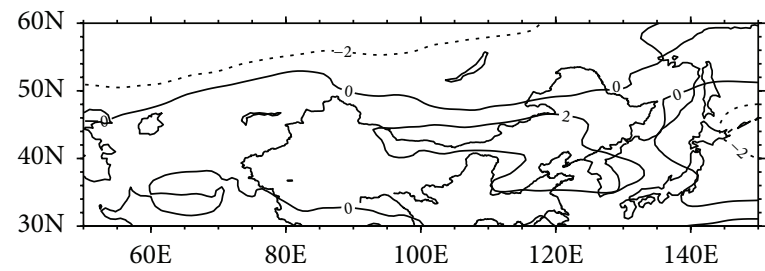

(f)

Figure 7: The correlation coefficient distribution between the total HDs in region A and u-component anomaly (m/s) at (a) $250 \mathrm{hPa}$, (c) $500 \mathrm{hPa}$, and (e) $700 \mathrm{hPa}$ during 1979-2013 summer, and the distribution of u-component anomaly of (b) $250 \mathrm{hPa}$, (d) $500 \mathrm{hPa}$, and (f) $700 \mathrm{hPa}$ in the summer of 2013. In (a, c, and e), the long-term trend is removed, and shaded area denotes the correlation coefficient significant at the 0.05 level.

The anomalous southerlies brought heat transport to the middle and lower reaches of the Yangtze River and contributed to the long-lasting heat wave. The northerly anomaly in the lower troposphere was located north of $44^{\circ} \mathrm{N}$ in the summer of 2013. The transport of cold air in the middle and high latitudes was more northward, and it was difficult for the cold air to reach the middle and lower reaches of the Yangtze River. The weak transport of cold air from north was one of the direct causes of the severe heat wave in the middle of the Yangtze River in the summer of 2006 [24]. Xiang et al. [67] also indicated that the transport of cold air in the Yangtze River Valley was weaker and more northward than usual during the hot spell in 2013.

4.4. The Anomaly of Arctic Polar Vortex. The Arctic polar vortex was a deep atmospheric system in the middle and high latitudes of northern hemisphere and played a vital role in global climate. As early as in 1949, Willett [69] took into consideration the impact of the expanding and reducing of the Arctic polar vortex on weather and climate. Meteorologists in China noticed that the Arctic polar vortex played a significant role on climate change in China in the 1980s, especially on temperature [70]. There was a close relationship between the area and intensity of the Arctic polar vortex and the position of subtropical high and summer rainfall belt in China [71]. The intensity of the Arctic polar vortex and the WPSH were the major reasons for the flood and drought disasters in the Yangtze River and Huaihe River Valley [72]. Weak Arctic polar vortex and strong WPSH were favorable for hot spell in China [73]. In the summer of 2003, the Arctic polar vortex was in the western hemisphere for a long time, and weak cold air and persistent high temperature were observed in southern China [23].

Figure 9 shows the distribution of climate mean geopotential height at $500 \mathrm{hPa}$ in the northern hemisphere and the anomaly in the summer of 2013. For the climate mean, the center of the Arctic polar vortex concentrated in the Arctic pole, and four troughs extending from the polar vortex were located in northern Canada, northern Qinghai-Tibet Plateau, the central Pacific, and the west coast of Europe, respectively, while four ridges were situated between the troughs. The North American trough located in northern Canada was the deepest, and the trough located in the west coast of Europe was the shallowest. Besides the westerly troughs stretching out from the polar vortex, there were also troughs in the middle and high latitudes near the Black Sea, northeastern Inner Mongolia, and the west coast of North America. Compared with the climate mean, the intensity of the Arctic polar vortex was obviously stronger in the summer of 2013, with the center of the anomaly lower than $-70 \mathrm{gpm}$. The polar vortex obviously extended to the western hemisphere, and the negative anomaly was concentrated in northeastern Canada and Greenland, while the positive anomaly circled around the negative anomaly. In the summer 


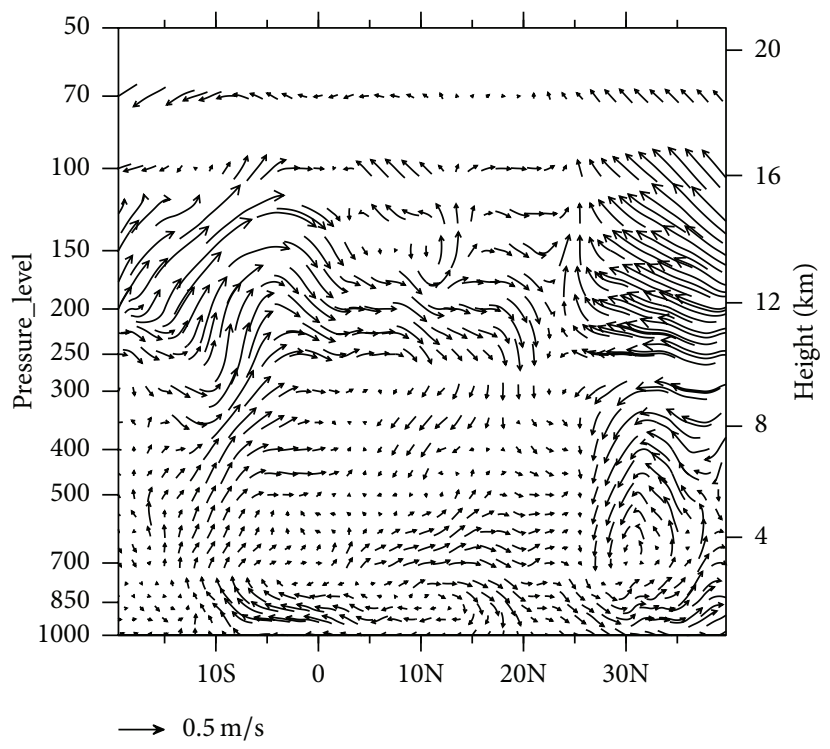

(a)

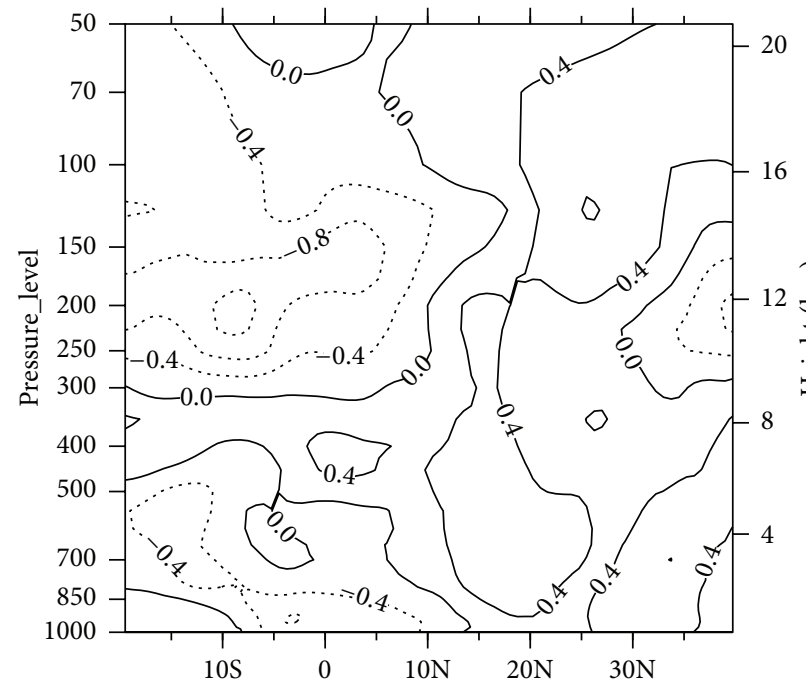

(b)

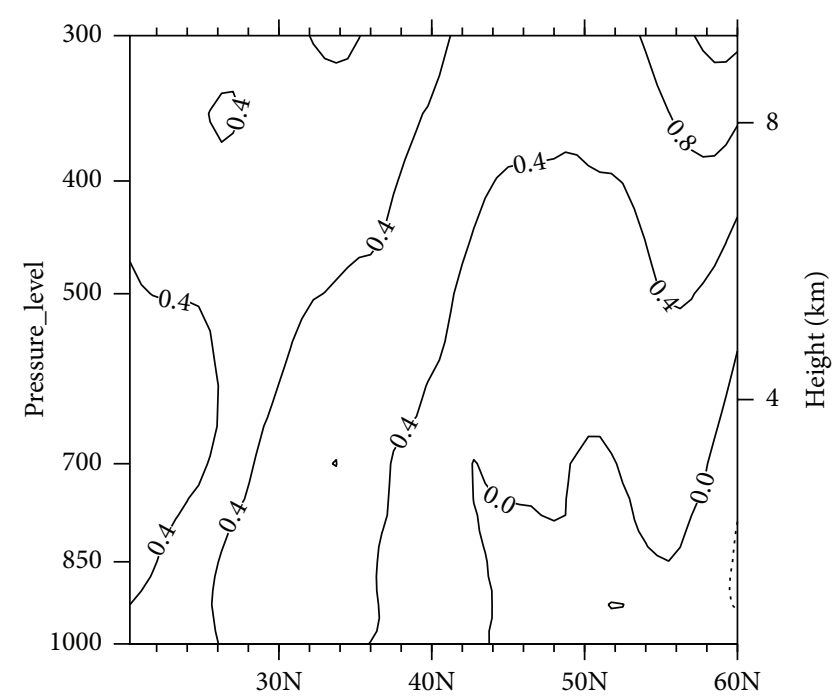

(c)

Figure 8: The pressure-latitude profiles of $\mathrm{v}$-w wind anomaly $(\mathrm{m} / \mathrm{s})$ in (a) West Pacific $\left(110^{\circ} \mathrm{E}-180^{\circ} \mathrm{E}\right)$ and $\mathrm{v}$-component anomaly $(\mathrm{m} / \mathrm{s})$ in $(\mathrm{b})$ Southeast Asia $\left(90^{\circ} \mathrm{E}-130^{\circ} \mathrm{E}\right)$ and (c) Northeast Asia $\left(90^{\circ} \mathrm{E}-130^{\circ} \mathrm{E}\right)$.

of 2013, the ridges lying in these positive anomaly zonal regions would be stronger, and the troughs would be weaker than normal, so the northern part of trough in northern Qinghai-Tibet Plateau and the trough in central Pacific were weaker than normal. At the same time, the northern part of the westerly trough in northern Qinghai-Tibet Plateau was more eastward, and the southern part was more westward and merged into one trough with the trough near the Black Sea, combined with the climatic trough in the northeastern Inner Mongolia; a very broad trough in southwest-northeast direction was found in the middle and high latitudes of Eurasia (figure omitted). The westerly in the broad trough was straight and mostly affected the large area north of $40^{\circ} \mathrm{N}$. The straight westerly (enhanced westerly) blocked southward intrusion of the Arctic air mass, and this was unfavorable for the weakening of WPSH and disrupt of heat wave. The straight westerly was unfavorable for the cold air invading southward to the middle and lower reaches of the Yangtze River.

The area of the Asian polar vortex (AAPV) in $60^{\circ} \mathrm{E} \sim 150^{\circ} \mathrm{E}$ at $500 \mathrm{hPa}$ in the summer of 2013 was calculated. It was found that in June the AAPV was smaller than normal, and the south border of the Asian polar vortex was more northward, while in July and August the AAPV was larger and the south border was more southward. Ji et al. [74] pointed out that, in summer, the ridge of the WPSH was more southward when the AAPV over $500 \mathrm{hPa}$ was larger; on the contrary the ridge was more northward. In June 2013, the ridge of the WPSH was more northward locating in the middle and lower reaches of the Yangtze River. Compared with the abrupt 

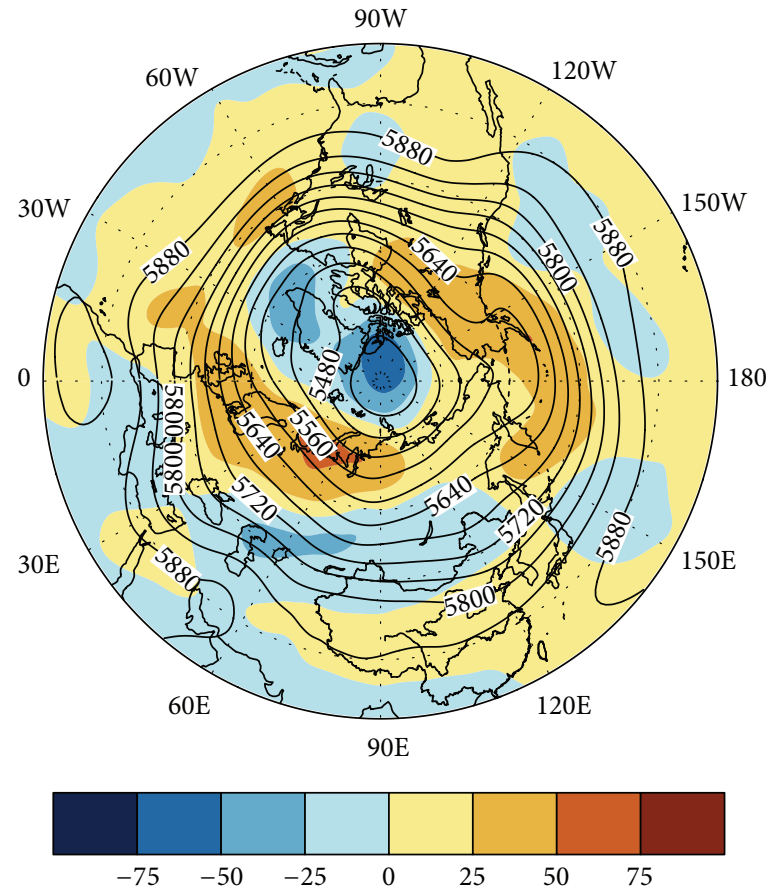

Figure 9: The distribution of climate mean geopotential height (solid line) and the anomaly (shaded area) in the summer 2013 at $500 \mathrm{hPa}$ in the northern hemisphere (gpm).

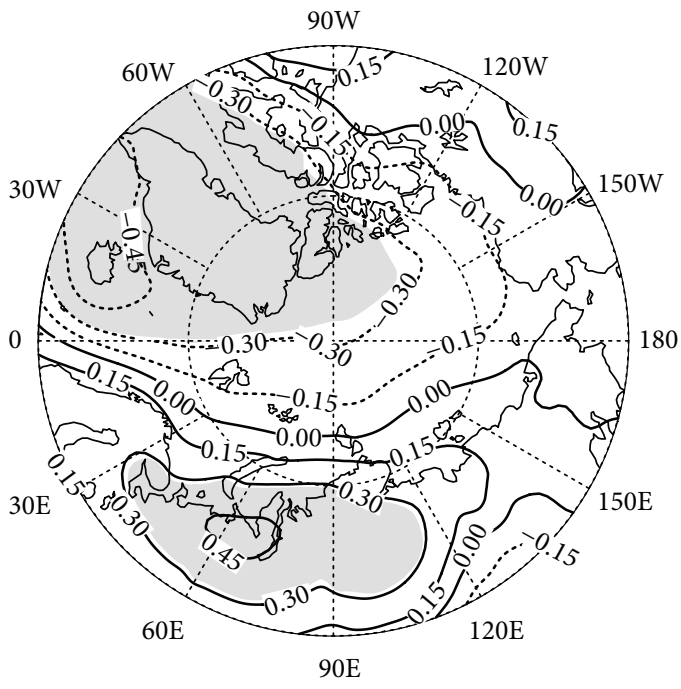

(a)

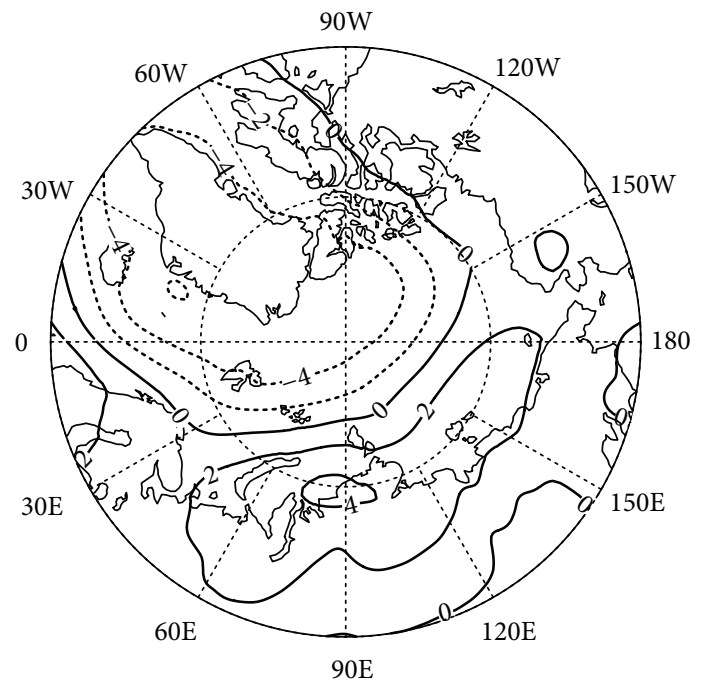

(b)

FIgURE 10: (a) The correlation coefficient distribution between the SLP anomaly in the Arctic region and the total HDs in region A during 1979-2013 summer, and (b) the distribution of the SLP anomaly (hPa) in the summer of 2013. In (a), long-term trend is removed, and shaded area denotes the correlation coefficient significant at the 0.05 level.

northward movement to the lower reaches of the Yellow River and the Huaihe River Valley in normal years, the ridge in July and August of 2013 was more southward, still locating in the middle and lower reaches of the Yangtze River. The ridge of the WPSH sustained in the middle and lower reaches of the Yangtze River, as shown in Figure 4, resulting in the rare persistent hot spell.
Figure 10 shows the correlation coefficient distribution between the sea-level pressure (SLP) anomaly and the total HDs and the distribution of the SLP anomaly in the summer of 2013. The SLP anomaly in northeastern Canada, Greenland, and Iceland was significantly negatively correlated with the total HDs in region $\mathrm{A}$, and the correlation coefficient near Iceland was below -0.45 . Significant positive correlation 


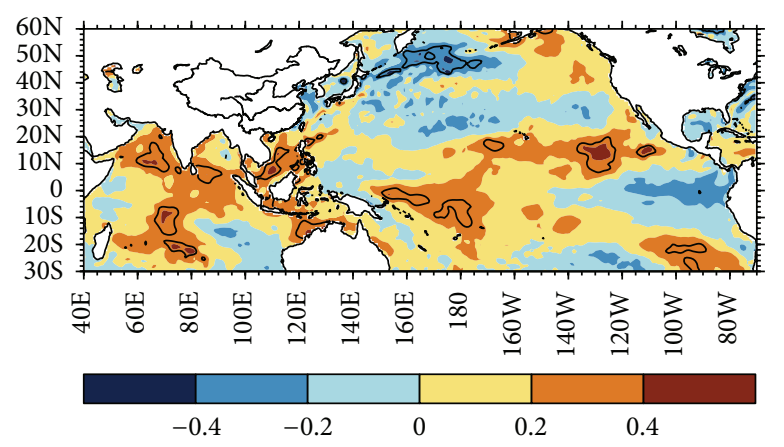

(a)

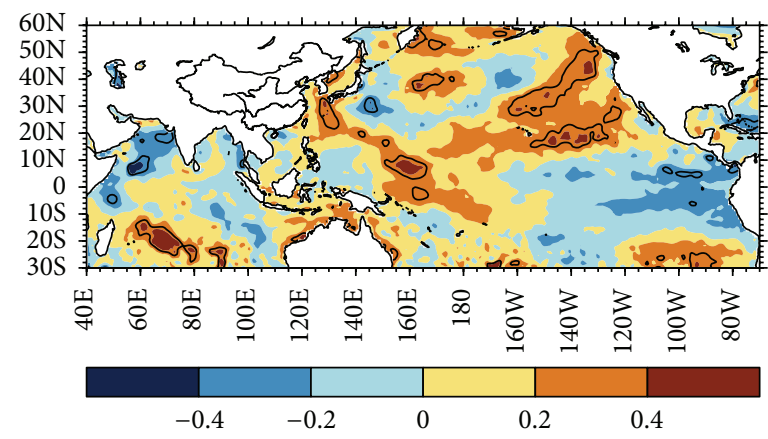

(c)

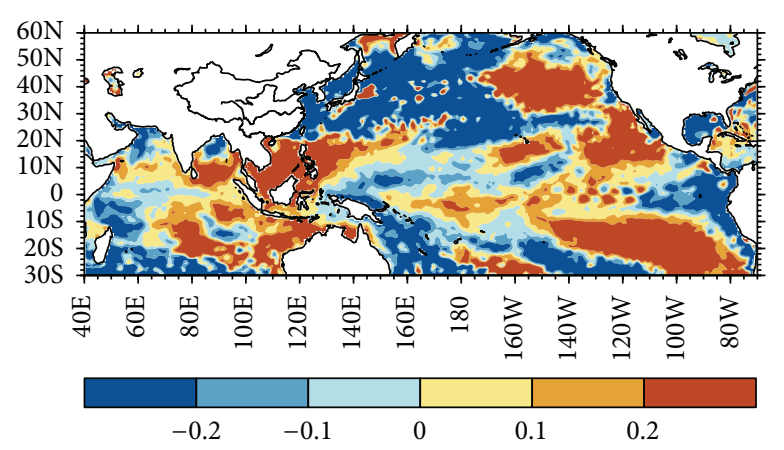

(b)

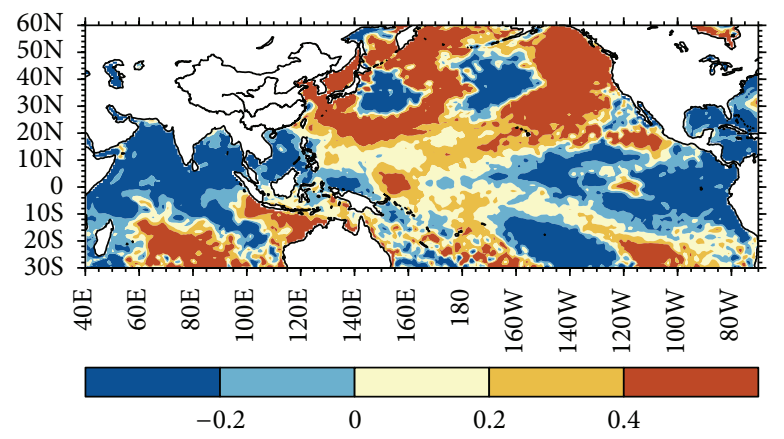

(d)

FIGURE 11: The correlation coefficient distribution between the total HDs in region A in summer and SSTA in (a) spring and (c) summer during 1979-2013, and the distribution of SSTA $\left({ }^{\circ} \mathrm{C}\right.$ ) in (b) spring and (d) summer in 2013. In (a and c), long-term trend is removed, and solid line denotes the correlation coefficient significant at the 0.05 level.

coefficient was found in the middle and northern East Europe and Siberia. The negative SLP anomalies were observed near Greenland in the summer of 2013, with $-6 \mathrm{hPa}$ lower than normal. The Arctic polar vortex was strong and biased towards Greenland, making the polar cold air active in this region. In summer, the continental low pressure was evident over the Eurasian continent. The continental low was weaker than normal in the summer of 2013, as positive SLP anomalies were located in northern Siberia with the highest anomaly above $4 \mathrm{hPa}$. This was unconducive to the strong cold air invading southward to the middle and lower reaches of the Yangtze River.

4.5. The Anomaly of SST in the Indian Ocean and the Pacific. In China, many meteorologists studied the impacts of SSTA on the WPSH and found that the SSTA in the Indian Ocean and the Pacific had a close relationship with the WPSH [75-80]. Areas of high positive correlation between WPSH and SSTA were located at the equatorial middle and eastern Pacific and the Indian Ocean [76]. When the western tropical Pacific warm pool is warming, the convection is intensified from the area around the Philippines to the Indo-China Peninsula through the South China Sea, the WPSH may shift northward, and the summer rainfall may be below normal in the Yangtze River Valley [75]. Three coupled oceanatmosphere phenomena in the Indo-Pacific Oceans, El Nino, El Nino Modoki, and the Indian Ocean Dipole (IOD) had possible influences on summer climate in China [81].
SSTA in the spring and summer in 2013 were favorable for more HDs in region A. SSTAs in the Indian Ocean and the Pacific in spring were related to the heat wave in region $A$ in summer. As Figure 11(a) shows, significant positive correlation was found between the total HDs in region A in summer and SSTA in spring in the warm pool of western equatorial Pacific, the South China Sea, the Arabian Sea, and the south of the Bengal Bay. In the spring of 2013, there were above $0.2^{\circ} \mathrm{C}$ positive anomalies from western Pacific to the South China Sea and the southern Bengal Bay (Figure 11(b)).

Figure 11(c) shows the distribution of the correlation coefficient between the SSTA in summer and the total HDs in region A. Significant positive correlation was found from the warm pool of the western equatorial Pacific to the northwestern Pacific. Significant negative correlation was found in the eastern equatorial Pacific and the Arabian Sea. Figure 11(d) shows that there were above $0.4^{\circ} \mathrm{C}$ positive anomalies from the warm pool of western equatorial Pacific to the northwestern Pacific, while below $-0.2^{\circ} \mathrm{C}$ negative anomalies in the eastern equatorial Pacific and the northern Indian Ocean. The thermal state in the tropical western Pacific warm pool and the convection over the warm pool play an important role in the summer climate anomalies in East Asia [75]. When the western tropical Pacific warm pool is warming, the upward motion is intensified in the tropical western Pacific, and the downward motion is intensified in the subtropical region, as shown in Figure 8(a). The WPSH may strengthen and HDs may be frequent in the Yangtze 


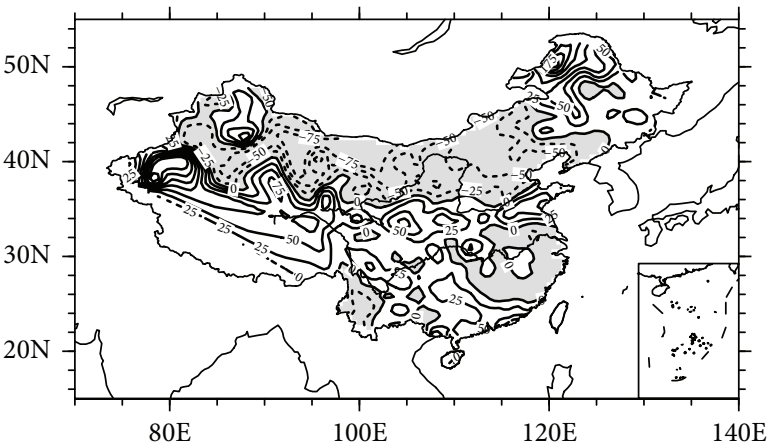

(a)

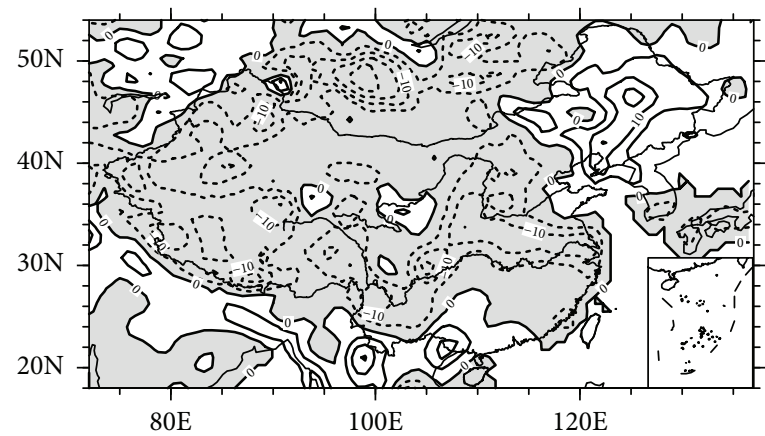

(c)

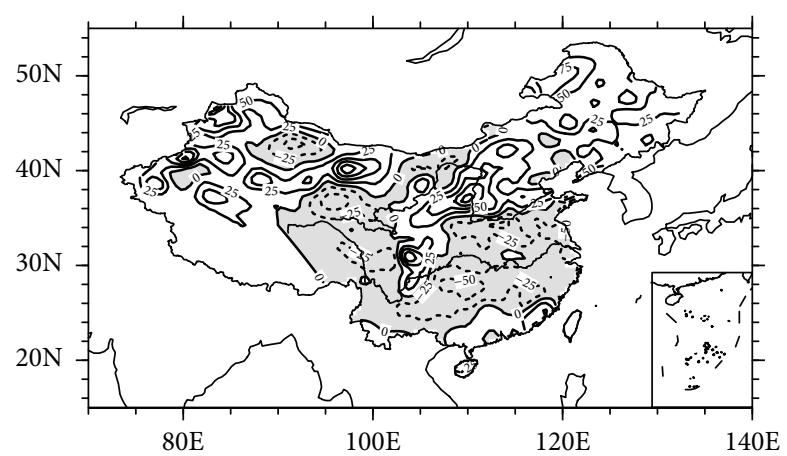

(b)

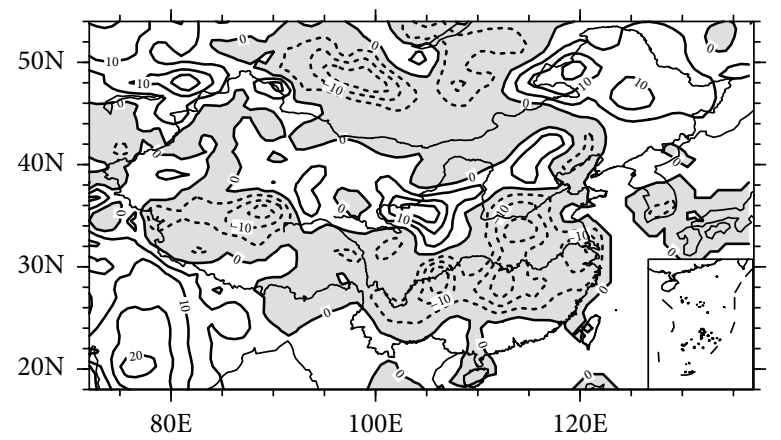

(d)

FIGURE 12: The percentage of precipitation anomalies in China in (a) spring and (b) summer of 2013 and the percentage of volumetric soil water anomalies in China in (c) spring and (d) summer of 2013. Shaded area denotes the negative percentage of precipitation and volumetric soil water anomalies.

River Valley. Besides, from a large scale over the tropical Indo-Pacific Oceans, above-normal SSTA is found in the tropical western Pacific in the summer of 2013, while belownormal SSTA in the tropical central and eastern Pacific and the tropical Indian Ocean. In association with SSTA in the tropical Indo-Pacific Oceans, the convection was stronger in the tropical western Pacific and weaker in the tropical central and eastern Pacific and tropical Indian Ocean (figures omitted). The distribution of SSTA in the tropical IndoPacific Oceans in the summer of 2013 favors the upward motion over the tropical western Pacific and helps the Hadley cell enhancement and the strengthening of the WPSH.

4.6. The Anomaly of the Soil Moisture. In the spring of 2013, the precipitation in the middle and lower reaches of the Yangtze River was less than normal and in some areas even $25 \%$ less (Figure 12(a)). In the summer of 2013, Meiyu began later and ended earlier than normal in the middle and lower reaches of the Yangtze River [82, 83], and the precipitation brought by typhoons was also less $[67,80]$. The percentage of precipitation anomaly around the Yangtze River region in summer was 25\% 50\% less than normal (Figure 12(b)). Accordingly in the spring and summer, the volumetric soil water around the Yangtze River region was about 10\% less than normal and in some regions even $15 \%$ less (Figures $12(\mathrm{c})$ and $12(\mathrm{~d}))$. Heat waves can be amplified by the dry soil conditions in the regions with precipitation deficits [8286]. The moisture deficits in soil in spring and summer made the heat wave more serious in the middle and lower reaches of the Yangtze River. Besides, the clouds in wet regions reduce the incoming solar radiation resulting in lower surface temperature, and dry conditions under subtropical high system favor more sunshine resulting in higher surface temperature [81]. A good negative correlation was found between summer rainfall and high temperature anomalies in South China [15].

\section{Summary and Conclusions}

An exceptional heat wave event occurred in southern China from June to August in 2013, and the total HDs were 25 days more than normal and exceeded the 90th percentile by over 10 days. In this paper, the 2013 heat wave was described, and the associated atmospheric circulations as well as the anomaly of the underlying surfaces were investigated.

The anomaly of the WPSH was the major and direct reason for the heat wave in 2013. In the summer of 2013, the WPSH underwent four westward extensions to the middle and lower reaches of the Yangtze River and brought about four hot spells to the Yangtze River Valley. The extension of the WPSH from late July to mid-August was the most westward. The ridge of the WPSH was more northward in June, more southward in July and August, and sustained between $25^{\circ}$ and $30^{\circ} \mathrm{N}$ all summer. The anomalies of the WPSH ridge made the hot weather come earlier and sustain in the middle and lower reaches of the Yangtze River. 
The anomaly of the WPSH was connected with the circulation anomaly in high latitudes and low latitudes. In high latitudes, the central position of the Arctic polar vortex was biased in the western hemisphere. In June 2013, the AAPV was smaller and the south border was more northward, while in July and August the AAPV was greater and the south border was more southward. The anomaly of AAPV made the WPSH ridge more northward in June, more southward in July and August, and sustain in the middle and lower reaches of the Yangtze River. At $500 \mathrm{hPa}$, the ridges lying in these zonal regions with positive anomaly became stronger, and the northern part of trough in the northern Qinghai-Tibet Plateau and the trough in the central Pacific were weaker than normal. The westerly trough was vast and flat in the northern China, and the zonal circulation was unfavorable for the weakening of the WPSH. At $700 \mathrm{hPa}$, the westerly wind was stronger from Northeast China to the Korean Peninsula and unconducive to the strong cold air invading southward to the middle and lower reaches of the Yangtze River and weakening the heat wave.

In low latitudes, the center of the $\mathrm{SAH}$ at $150 \mathrm{hPa}$ was located near $80^{\circ} \mathrm{E}$ in the summer of 2013 , and the highest geopotential height anomaly at $150 \mathrm{hPa}$ was in the Yellow River Valley. The SAH was overall more eastward and more northward in the summer of 2013, meanwhile the WPSH was more westward and stronger. Besides, the ITCZ in the central and western tropical Pacific was weaker during the whole summer of 2013. The northerly anomaly dominated in the lower troposphere in the tropical Pacific. The effects by tropical easterly waves (a kind of wave moving from east to west across the tropics) and typhoons in the south of the WPSH were weak when the ridge moved southward in the second half of July to early August, which were unfavorable for the weakening of heat wave. The strong southerly prevailed in the middle and lower reaches of the Yangtze River in the summer of 2013. The Hadley circulation in the northern hemisphere was stronger in the central and western Pacific. The upward motion in the central and western Pacific and downward motion in the subtropical region contributed to the strengthening of the WPSH. Meanwhile, anticyclone anomaly near $28^{\circ} \mathrm{N}$ indicated the strengthening of the WSPH.

The heat wave in the middle and lower reaches of the Yangtze River in the summer of 2013 was closely correlated with SSTA in the Indian and Pacific oceans. The positive SSTA was found in the warm pool of the western equatorial Pacific to the northwestern Pacific while negative anomalies in the eastern equatorial Pacific and the northern Indian Ocean in the summer of 2013 were found. The dynamical linkages between the SSTA in the Indian Ocean and the Pacific and the heat wave around Yangtze River regions were complex and worth further investigating. The convection and upward flow were stronger over the tropical western Pacific, while the convection was weak and downward flow was confined in the eastern Pacific and the tropical Indian Ocean. The warming in the warm pool of the tropical western Pacific could drive ascending anomalous flow in the tropical region and the enhancement of the Hadley circulation. Strong descending anomalous flow was observed in the subtropical region, connecting with the strengthening of the WPSH. However, the positive SSTA over the northwestern Pacific within 20$30^{\circ} \mathrm{N}$ in the summer of 2013 might be favorable for an upward motion in the local area. The precise mechanism responsible for their association needs to be further investigated. Besides, statistically significant correlation values existed over remote areas such as the west of Mexico westward to the Hawaiian Islands, the southeastern Pacific near the Easter Island, and the central of the southern Indian Ocean. But it was not clear whether there was an important remote dynamical process (e.g., teleconnection) that could affect HDs in China. The numerical model will be applied in further study to see whether and how the SSTA in remote areas affects the atmospheric circulation and therefore influence the heat wave.

\section{Conflict of Interests}

The authors declare that there is no conflict of interests regarding the publication of this paper.

\section{Acknowledgments}

The authors thank the anonymous reviewers and editors for their helpful comments and suggestions. The authors thank Dr. Kaijun Wu for his help on data calculation and processing. This research was supported by the National Natural Science Foundation of China (Grant no. 41205039) and China Meteorological Administration Special Public Welfare Research Fund (GYHY201206017 and GYHY201306033).

\section{References}

[1] D. L. Hartmann, A. M. G. Klein Tank, M. Rusticucci et al., "Observations: atmosphere and surface," in Climate Change 2013: The Physical Science Basis. Contribution of Working Group I to the Fifth Assessment Report of the Intergovernmental Panel on Climate Change, Cambridge University Press, Cambridge, UK, 2013.

[2] A. Davis, Heat Claims As Many As 38 People, Tests State Energy Supply, Associated Press, San Jose Mercury News, 2006.

[3] K. Knowlton, M. Rotkin-Ellman, G. King et al., “The 2006 California heat wave: impacts on hospitalizations and emergency department visits," Environmental Health Perspectives, vol. 117, no. 1, pp. 61-67, 2009.

[4] O. Munoz, 139 Deaths Later, Heat Wave Appears Over, Associated Press, Forbes, New York, NY, USA, 2006.

[5] USAgNet, California’s cattle death toll surpasses 25000, 2006.

[6] L. Feudale and J. Shukla, "Influence of sea surface temperature on the European heat wave of 2003 summer. Part I: an observational study," Climate Dynamics, vol. 36, no. 9-10, pp. 1691-1703, 2011.

[7] C. Schär, P. L. Vidale, D. Lüthi et al., "The role of increasing temperature variability in European summer heatwaves," Nature, vol. 427, no. 6972, pp. 332-336, 2004.

[8] M. Beniston, "The 2003 heat wave in Europe: a shape of things to come? An analysis based on Swiss climatological data and model simulations," Geophysical Research Letters, vol. 31, no. 2, 2004. 
[9] G. A. Meehl and C. Tebaldi, "More intense, more frequent, and longer lasting heat waves in the 21st century," Science, vol. 305, no. 5686, pp. 994-997, 2004.

[10] L. Feudale and J. Shukla, "Influence of sea surface temperature on the European heat wave of 2003 summer. Part II: a modeling study," Climate Dynamics, vol. 36, no. 9-10, pp. 1705-1715, 2011.

[11] D. Barriopedro, E. M. Fischer, J. Luterbacher, R. M. Trigo, and R. García-Herrera, "The hot summer of 2010: redrawing the temperature record map of Europe," Science, vol. 332, no. 6026, pp. 220-224, 2011.

[12] R. Dole, M. Hoerling, J. Perlwitz et al., "Was there a basis for anticipating the 2010 Russian heat wave?" Geophysical Research Letters, vol. 38, no. 6, Article ID L06702, 2011.

[13] K. E. Trenberth and J. T. Fasullo, "Climate extremes and climate change: the Russian heat wave and other climate extremes of 2010," Journal of Geophysical Research: Atmospheres, vol. 117, no. 17, Article ID D17103, 2012.

[14] M. Hoerling, A. Kumar, R. Dole et al., "Anatomy of an extreme event," Journal of Climate, vol. 26, no. 9, pp. 2811-2832, 2013.

[15] T. Ding, W. H. Qian, and Z. W. Yanb, "Changes in hot days and heat waves in China during 1961-2007," International Journal of Climatology, vol. 30, no. 10, pp. 1452-1462, 2010.

[16] T. Ding and W. Qian, "Geographical patterns and temporal variations of regional dry and wet heatwave events in China during 1960-2008," Advances in Atmospheric Sciences, vol. 28, no. 2, pp. 322-337, 2011.

[17] Y. J. Wang, F. M. Ren, and X. B. Zhang, "Spatial and temporal variations of regional high temperature events in China," International Journal of Climatology, vol. 34, no. 10, pp. 30543065, 2014.

[18] H. J. Ding, L. L. Zhou, B. Zha et al., "An analysis on the abnormal high temperature weather in the south Yangtze Valley during summer 2003," Journal of Zhejiang University (Science Edition), vol. 34, no. 1, pp. 100-105, 2007 (Chinese).

[19] R. Guo and X. F. Zhi, "Synoptic analysis of severe droughts during the summer 2003 in Southern China," Journal of Nanjing Institute of Meteorology, vol. 31, no. 2, pp. 234-241, 2008 (Chinese).

[20] J. H. Sun, J. Wei, and X. L. Zhang, "The abnormal weather in the summer 2003 and its real-time prediction," Climatic and Environmental Research, vol. 9, no. 1, pp. 203-217, 2004 (Chinese).

[21] H. Yang and C. Y. Li, "Diagnostic study of serious high temperature over South China in 2003 summer," Climatic and Environmental Research, vol. 10, no. 1, pp. 80-85, 2003 (Chinese).

[22] Y. L. Fang and M. Q. Jian, "Diagnosis study of persistent heat waves in South China during summer 2003," Journal of Tropical Oceanography, vol. 30, no. 3, pp. 30-37, 2011 (Chinese).

[23] R. P. Zhang, Y. F. Zhou, and K. Y. Guo, "The relation between the persistent high temperature in south of china in the summer of 2003 and the vortex's position," Scientia Meteorological Sinica, vol. 25, no. 5, pp. 528-533, 2005 (Chinese).

[24] X. K. Zou and H. Gao, "Analysis of severe drought and heat wave over the Sichuan Basin in the summer of 2006," Advances in Climate Change Research, vol. 3, no. 3, pp. 149-153, 2007 (Chinese).

[25] M. Zhang, Q. J. Gao, and W. Jiang, "The preliminary analysis of heat wave in summer of 2009 in China," Journal of the Meteorological Sciences, vol. 31, no. 5, pp. 582-590, 2011 (Chinese).
[26] T. Ding and Z. J. Ke, "Characteristics and changes of regional wet and dry heat wave events in China during 1960-2013," Theoretical and Applied Climatology, 2014.

[27] H. X. Duan, S. P. Wang, and J. Y. Feng, "The national drought situation and its impacts and causes in the summer 2013," Journal of Arid Meteorology, vol. 31, no. 3, pp. 633-640, 2013 (Chinese).

[28] China Meteorological Administration, Surface Meteorological Observation Criteria, China Meteorological Press, Beijing, China, 2003, (Chinese).

[29] Q. Li, X. Liu, H. Zhang, T. C. Peterson, and D. R. Easterling, "Detecting and adjusting temporal inhomogeneity in Chinese mean surface air temperature data," Advances in Atmospheric Sciences, vol. 21, no. 2, pp. 260-268, 2004.

[30] Q. X. Li, H. Z. Zhang, X. N. Liu, and J. Huang, "Urban heat island effect on annual mean temperature during the last 50 years in China," Theoretical and Applied Climatology, vol. 79, no. 3-4, pp. 165-174, 2004.

[31] D.-Y. Gong, Y.-Z. Pan, and J.-A. Wang, "Changes in extreme daily mean temperatures in summer in eastern China during 1955-2000," Theoretical and Applied Climatology, vol. 77, no. 12, pp. 25-37, 2004.

[32] Y. Tang, J. Gan, L. Zhao, and K. Gao, "On the climatology of persistent heavy rainfall events in China," Advances in Atmospheric Sciences, vol. 23, no. 5, pp. 678-692, 2006.

[33] Z. Y. Wang and Y. H. Ding, "Climate change of the cold wave frequency of China in the last 53 years and the possible reasons," Chinese Journal of Atmospheric Sciences, vol. 30, pp. 14-22, 2006 (Chinese).

[34] W. H. Qian, J. L. Fu, and Z. W. Yan, "Decrease of light rain events in summer associated with a warming environment in China during 1961-2005," Geophysical Research Letters, vol. 34, no. 11, Article ID L11705, 2007.

[35] J. Shi, Y. H. Ding, and L. L. Cui, "Climatic characteristics and their changing law during summer high-temperature times in East China," Acta Meteorologica Sinica, vol. 63, no. 3, pp. 237246, 2008 (Chinese).

[36] T. Ding and W. H. Qian, "Statistical characteristics of heat wave precursors in China and model prediction," Chinese Journal of Geophysics, vol. 55, pp. 1472-1486, 2012 (Chinese).

[37] W. H. Qian and T. Ding, "Atmospheric anomaly structures and stability associated with heat wave events in China," Chinese Journal of Geophysics, vol. 55, pp. 1487-1500, 2012 (Chinese).

[38] S. Feng, Q. Hu, and W. H. Qian, "Quality control of daily meteorological data in China, 1951-2000: a new dataset," International Journal of Climatology, vol. 24, no. 7, pp. 853-870, 2004.

[39] IPCC, Climate Change 2007, Working Group I Contribution to the Fourth Assessment Report of the IPCC Intergovernmental Panel on Climate Change, Cambridge University Press, Cambridge, UK, USA, 2007.

[40] P. D. Jones, E. B. Horton, C. K. Folland, M. Hulme, D. E. Parker, and T. A. Basnett, "The use of indices to identify changes in climatic extremes," Climatic Change, vol. 42, no. 1, pp. 131-149, 1999.

[41] X. H. Pan and P. M. Zhai, "Analysis of surface air temperature extremes," Meteorological Monthly, vol. 28, pp. 28-31, 2002 (Chinese).

[42] Z. Yan, P. D. Jones, T. D. Davies et al., "Trends of extreme temperatures in Europe and China based on daily observations," Climatic Change, vol. 53, no. 1-3, pp. 355-392, 2002. 
[43] L. J. Hua, Z. G. Ma, and Z. M. Zeng, “The comparative analysis of the changes of extreme temperature and extreme diurnal temperature range of large cities and small towns in Eastern China," Chinese Journal of Atmospheric Sciences, vol. 30, pp. 8091, 2006 (Chinese).

[44] X. Q. Fang, A. Y. Wang, S.-K. Fong, W. Lin, and J. Liu, "Changes of reanalysis-derived Northern Hemisphere summer warm extreme indices during 1948-2006 and links with climate variability," Global and Planetary Change, vol. 63, no. 1, pp. 6778, 2008.

[45] J. Y. Huang, Meteorological Statistical Analysis and Forecasting Method, China Meteorological Press, Beijing, China, 2004, (Chinese).

[46] T. Ding and Z. J. Ke, "A comparison of statistical approaches for seasonal precipitation prediction in Pakistan," Weather and Forecasting, vol. 28, no. 5, pp. 1116-1132, 2013.

[47] Z. Q. Gong, Y. J. Wang, Z. Y. Wang et al., "Briefly analysis on climate anomalies and causations in summer 2013," Meteorological Monthly, vol. 40, no. 1, pp. 119-125, 2014 (Chinese).

[48] T. Tang, R. H. Jin, X. Y. Peng et al., "Analysis on extremely high temperature over southern China in summer 2013," Meteorological Monthly, vol. 40, no. 10, pp. 1207-1215, 2014 (Chinese).

[49] J.-B. Peng, "An investigation of the formation of the heat wave in Southern China in summer 2013 and the relevant abnormal subtropical high activities," Atmospheric and Oceanic Science Letters, vol. 7, no. 4, pp. 286-290, 2014.

[50] R. Zhang, "Characteristics of soliton with dynamic constraints on its existence/propagation in tropical easterly wave," Advances in Atmospheric Sciences, vol. 13, no. 3, pp. 325-339, 1996.

[51] Q. Zhang and Y. F. Qian, "Interannal and interdecadal variations of the South Asia High," Chinese Journal of Atmospheric Sciences, vol. 24, no. 1, pp. 67-78, 2000 (Chinese).

[52] S. Y. Tao and F. K. Zhu, "The 100-MB flow patterns in Southern Asia in summer and its relation to the advance and retreat of the west-Pacific subtropical anticyclone over the Far East," Acta Meteorologica Sinica, vol. 34, no. 4, pp. 385-396, 1964 (Chinese).

[53] G. X. Wu, J. F. Chou, Y. M. Liu, Q. Zhang, and S. Sun, "Review and prospect of the study on the subtropical anticyclone," Chinese Journal of Atmospheric Sciences, vol. 27, no. 4, pp. 503517, 2003 (Chinese).

[54] S. S. Huang, "Relationship between the development of subtropical high on summer ocean and Tibetan high," Journal of Nanjing University: Science Edition, vol. 1, pp. 141-146, 1977 (Chinese).

[55] R. C. Ren and G. X. Wu, "On the short-term structure and formation of the subtropical anticyclone in the summer of 1998," Acta Meteorological Sinica, vol. 61, no. 2, pp. 180-195, 2003 (Chinese).

[56] B. K. Zhao, X. P. Yao, and G. X. Wu, "The structure and activity characteristics of the Western Pacific Subtropical anticyclone and its dynamical mechanism during the meiyu period over the Huaihe River basin in 2003," Chinese Journal of Atmospheric Sciences, vol. 29, no. 5, pp. 771-779, 2005 (Chinese).

[57] Y. H. Li, J. M. Qing, Q. Li et al., "Inter-annual and inter-decadal variations of South Asian High in summer and its influences on flood/drought over western Southwest China," Journal of Southwest University, vol. 34, no. 9, pp. 1-11, 2012 (Chinese).

[58] Q. G. Zhu, J. R. Lin, S. W. Shou et al., The Principle and Method of Synoptic Meteorology, China Meteorological Press, Beijing, China, 2007, (Chinese).
[59] Q. Y. Zhang and S. Y. Tao, "The anomalous subtropical anticyclone in western Pacific and their association with circulation over East Asia during summer," Chinese Journal of Atmospheric Sciences, vol. 27, no. 3, pp. 369-380, 2003 (Chinese).

[60] Y. Y. Bai and Z. Y. Guan, "Principal modes of summertime zonal-mean flow and their relations with AO and ENSO," Acta Meteorologica Sinica, vol. 65, no. 3, pp. 372-382, 2007 (Chinese).

[61] J. Bjerknes, "A possible response of the atmospheric Hadley circulation to equatorial anomalies of ocean temperature," Tellus, vol. 18, no. 4, pp. 820-829, 1966.

[62] J. Bjerknes, "Atmosphere teleconnection from the equaterial Pacific," Monthly Weather Review, vol. 97, no. 4, pp. 163-172, 1969.

[63] Q. Y. Zhang and S. Y. Tao, "Influence of Asian mid-high latitude circulation on East Asian summer rainflall," Acta Meteorologic Sinica, vol. 56, no. 2, pp. 199-211, 1998 (Chinese).

[64] Q. Y. Zhang and S. Y. Tao, “Tropical and subtropical monsoon over East Asia and its influence on the rainfall over eastern China in summer," Quarterly Journal of Applied Meteorology, vol. 9, supplement 1, pp. 17-23, 1998 (Chinese).

[65] B. G. Bi, G. C. Zhang, and Z. C. Li, "The relationship of abnormal features of western pacific subtropical high and 2003 Huaihe River flood and cause exploration," Journal of Tropical Meteorology, vol. 20, no. 5, pp. 505-514, 2004 (Chinese).

[66] W. Qian, J. Li, and X. Shan, "Application of synoptic-scale anomalous winds predicted by medium-range weather forecast models on the regional heavy rainfall in China in 2010," Science China Earth Sciences, vol. 56, no. 6, pp. 1059-1070, 2013.

[67] S. Q. Xiang, S. F. Shu, X. Han et al., "Analysis of abnormal high temperature causes in the summer of 2013," Climate Change Research Letters, vol. 3, pp. 78-84, 2014 (Chinese).

[68] D. D. Yu, R. Zhang, Y. C. H. Zhao et al., "Correlation between the subtropical high abnormal longitudinal position and the East Asian summer monsoon system," Transactions of Atmospheric Sciences, vol. 37, no. 3, pp. 304-312, 2014 (Chinese).

[69] M. C. Willett, "Long-period fluctuations of general circulation of the atmosphere," Journal of Meteorology, vol. 6, pp. 34-50, 1949.

[70] H. D. Zhang, S. T. Gao, and Y. Liu, "Advances of research on polar vortex," Plateau Meteorology, vol. 27, no. 2, pp. 452-461, 2008 (Chinese).

[71] X. G. Zhang and F. Y. Wei, "The interrelation between the polar vortex and the subtropical high in north hemisphere," in The Long-Term Weather Forecast Papers, pp. 25-36, China Meteorological Press, Beijing, China, 1990, (Chinese).

[72] Z. L. Shi, "The cause analysis of the typical drought and flood years in the area between the Yangtze River and Huaihe River in summer since 1990," Meteorological Monthly, vol. 22, no. 9, pp. 35-38, 1996 (Chinese).

[73] L. Zhao, S. L. Li, F. H. Wang et al., "The character and cause analysis of high-temperature weather in the summer 2000 in the Daxinganling prefecture," Heilongjiang Meteorology, no. 4, pp. 4-5, 2001 (Chinese).

[74] F. Ji, J.-H. Zhao, Q. Shen, R. Zhi, and Z.-Q. Gong, "The distribution of large-scale drought/flood of summer in China under different configurations of monsoon and polar vortex," Acta Physica Sinica, vol. 63, no. 5, Article ID 059201, 2014 (Chinese).

[75] R. H. Huang and F. Y. Sun, "Impacts of the thermal state and convective activities in the Tropical Western Warm Pool on the summer climate anomalies in East Asia," Scientia Atmospherica Sinica, vol. 18, no. 2, pp. 456-464, 1994 (Chinese). 
[76] S. Sun and M. Ying, "Subtropical high anomalies over the western pacific and its relations to the asian monsoon and SST anomaly," Advances in Atmospheric Sciences, vol. 16, no. 4, pp. 559-568, 1999.

[77] M. Ying and S. Q. Sun, "A study on the response of subtropical high over the Western Pacific on the SST anomaly," Scientia Atmospherica Sinica, vol. 24, no. 2, pp. 193-206, 2000.

[78] G. R. Jiang, W. Y. Sha, and J. P. Cai, "Long-range variation relations between sea surface temperature over the north Pacific and Indian oceans and the west Pacific subtropical high in summer," Marine Forecasts, vol. 8, no. 1, pp. 16-23, 1991.

[79] L. S. Hao, W. S. Lu, J. Z. H. Min et al., "Mechanism for the impact of tropical SSTA on general circulation in summer," Journal of Nanjing Institute of Meteorology, vol. 30, no. 2, pp. 178-185, 2007.

[80] D. Si, Y. Yuan, T. Cui et al., "Anomalies of ocean and atmospheric circulation in 2013 and their impacts on climate in China," Meteorological Monthly, vol. 40, no. 4, pp. 494-501, 2014 (Chinese).

[81] H. Y. Weng, G. X. Wu, Y. M. Liu, S. K. Behera, and T. Yamagata, "Anomalous summer climate in China influenced by the tropical Indo-Pacific Oceans," Climate Dynamics, vol. 36, no. 3, pp. 769-782, 2011.

[82] L. Ferranti and P. Viterbo, "The European summer of 2003: sensitivity to soil water initial conditions," Journal of Climate, vol. 19, no. 15, pp. 3659-3680, 2006.

[83] Z. J. Ke, Y. G. Wang, and Z. S. Gong, "Review of the precursor and its application in summer climate prediction in 2013," Meteorological Monthly, vol. 40, no. 4, pp. 502-509, 2014 (Chinese).

[84] E. M. Fischer, S. I. Seneviratne, P. L. Vidale, D. Lüthi, and C. Schär, "Soil moisture-atmosphere interactions during the 2003 European summer heat wave," Journal of Climate, vol. 20, no. 20, pp. 5081-5099, 2007.

[85] S. I. Seneviratne, T. Corti, E. L. Davin et al., "Investigating soil moisture-climate interactions in a changing climate: a review," Earth-Science Reviews, vol. 99, no. 3-4, pp. 125-161, 2010.

[86] B. Mueller and S. I. Seneviratne, "Hot days induced by precipitation deficits at the global scale," Proceedings of the National Academy of Sciences of the United States of America, vol. 109, no. 31, pp. 12398-12403, 2012. 

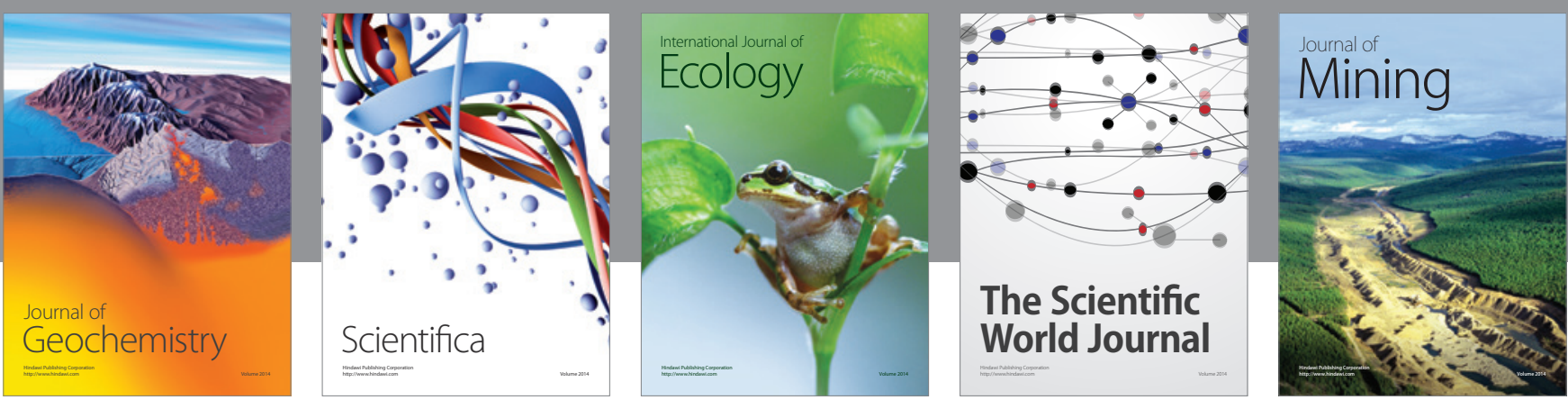

The Scientific World Journal
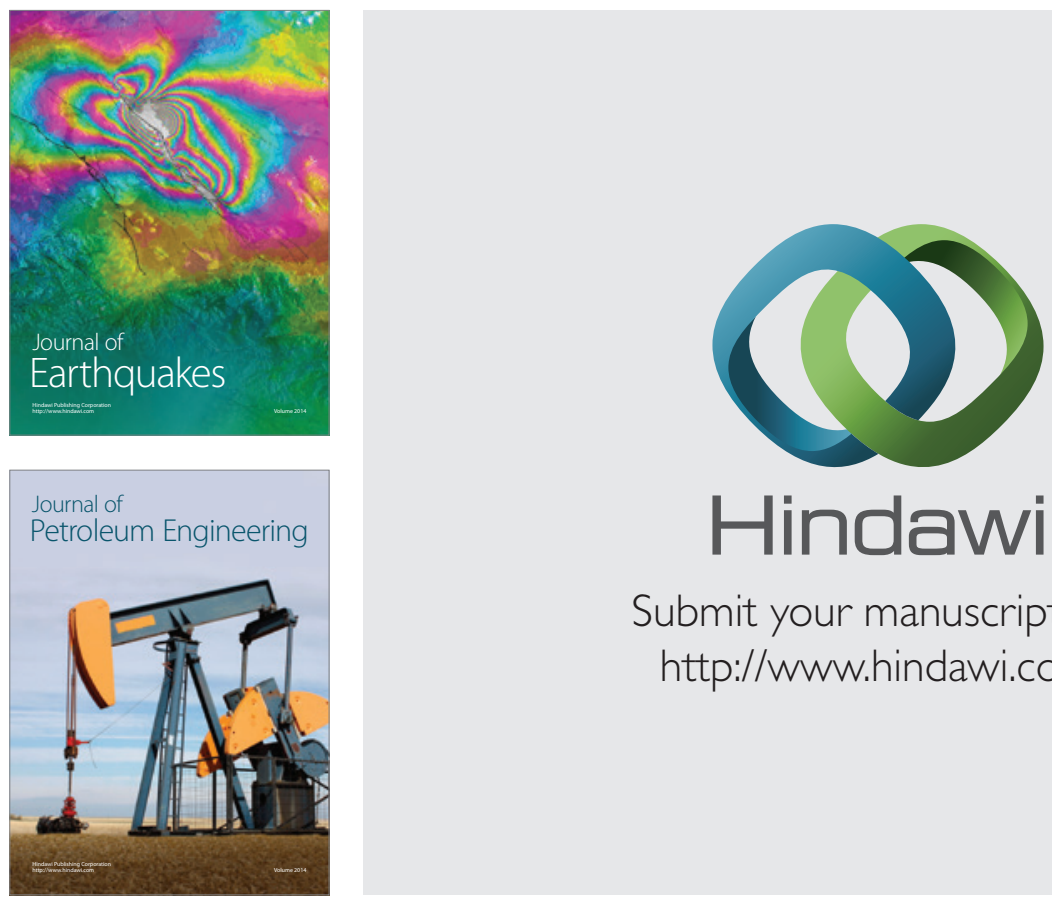

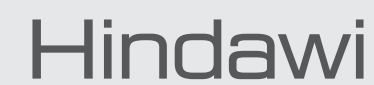

Submit your manuscripts at

http://www.hindawi.com
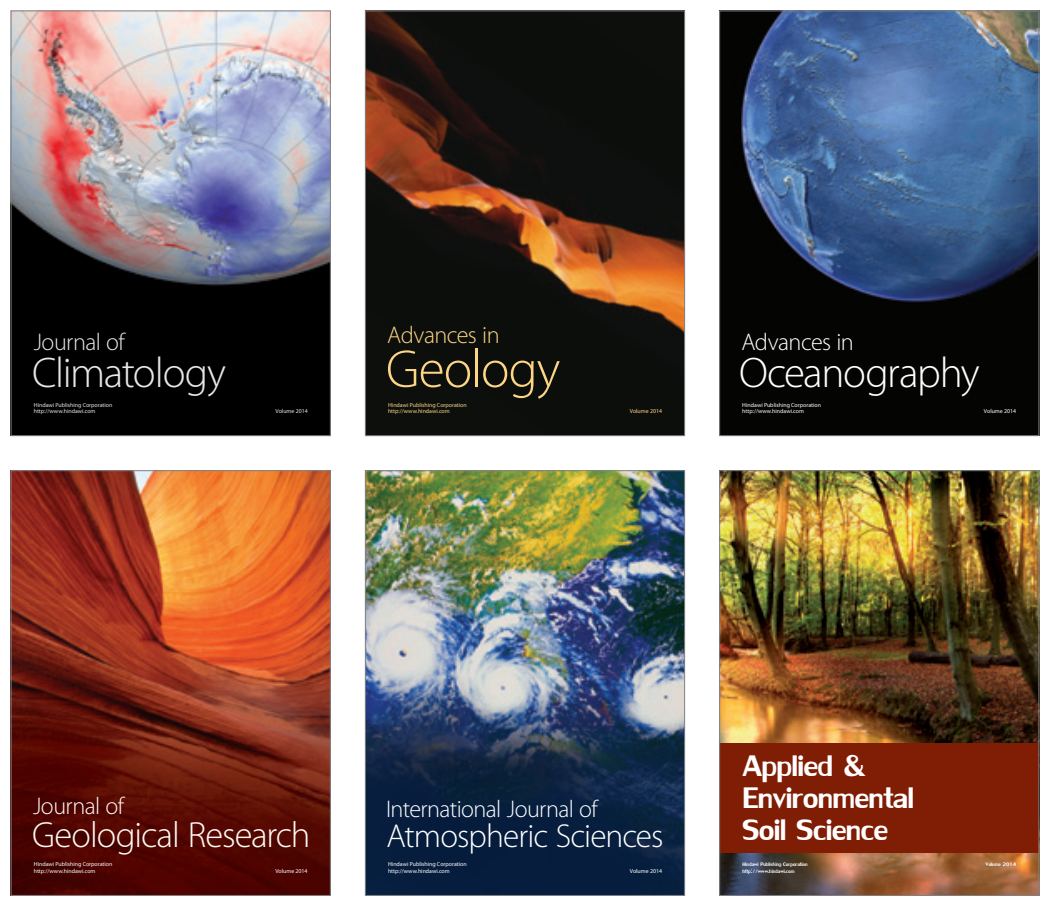
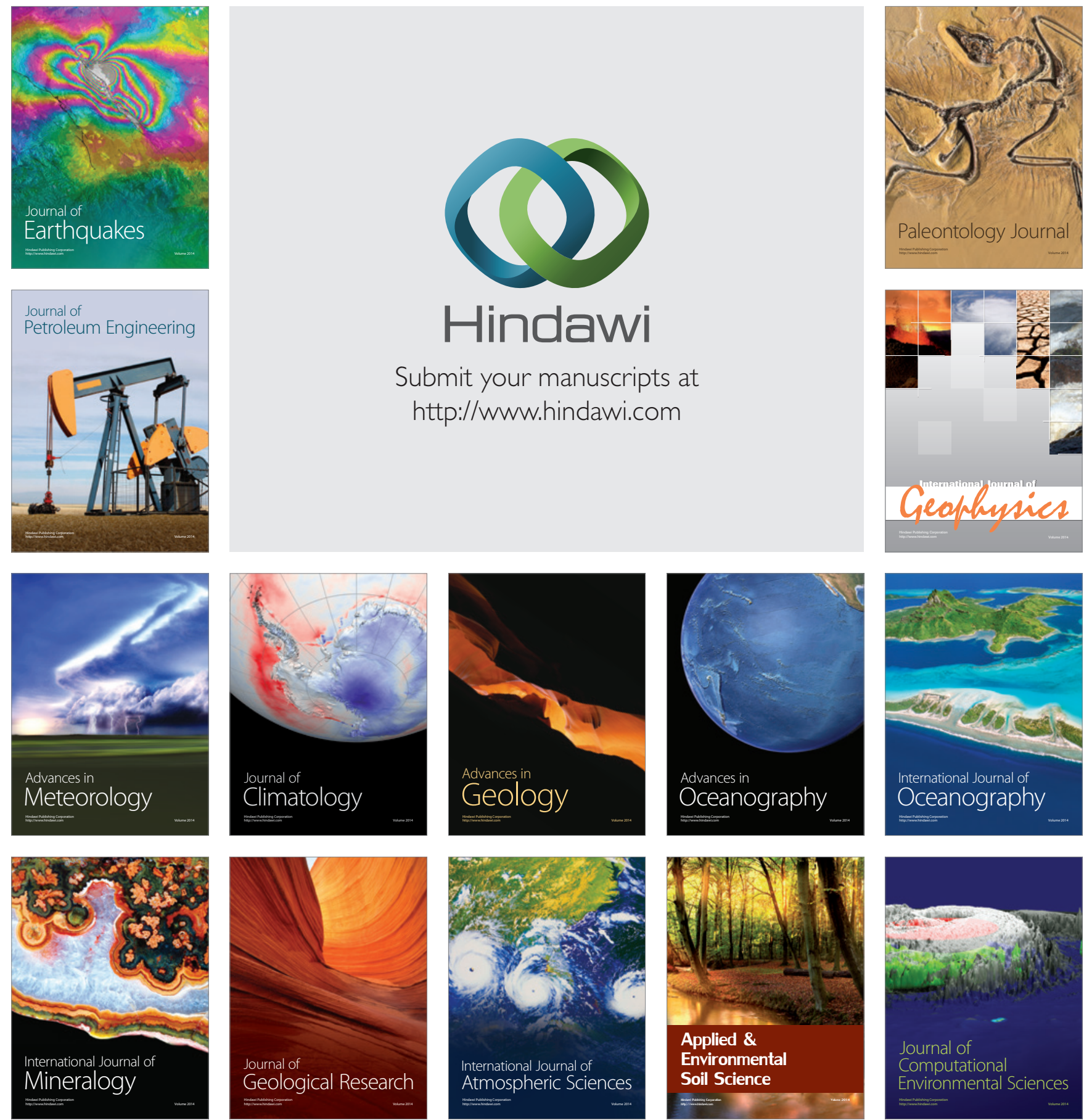